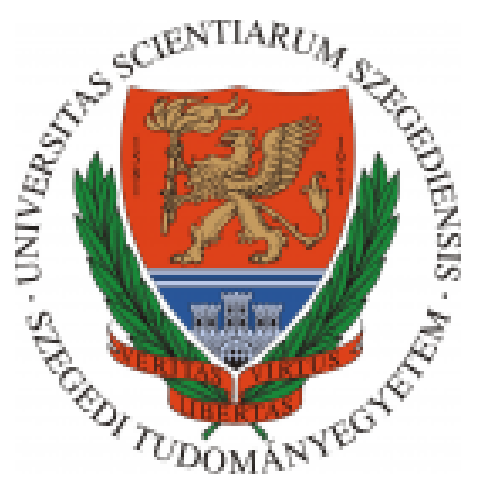

\title{
NEW APPROACHES IN THE ONCOLOGICAL TREATMENT OF METASTATIC PROSTATE CANCER
}

Ph.D. Thesis

Zsófia Küronya M.D.

Supervisor:

Anikó Maráz M.D., Ph.D.

University of Szeged, Faculty of Medicine

Doctoral School of Clinical Medicine

Szeged

2018 
List of full papers that served as the basis of the Ph.D. thesis

I. Küronya Z, Sükösd F, Varga L, Bíró K, Gyergyay F, Géczi L, Nagyiványi K, Jorgo K, Szarvas T, Kovács Á, Varga Z, Pepó J, Maráz A

ERG Expression Can Predict the Outcome of Docetaxel Combined with Androgen

Deprivation Therapy in Metastatic Hormone-Sensitive Prostate Cancer

Urol Oncol. 2018; $\quad$ In press

IF:3.397

II. Küronya Z, Sinkovics I, Ágoston P, Bíró K, Bodrogi I, Böde I, Dank M, Gyergyay F, Vajdics T, Kolonics Z, Nagyiványi K, Rúzsa Á, Géczi L

A Retrospective Analysis of the First 41 mCRPC Patients with Bone Pain Treated with Radium-223 at the National Institute of Oncology in Hungary.

Pathol Oncol Res. 2017 Oct;23(4):777-783.

IF:1.935

III. Biró K, Budai B, Szőnyi M, Küronya Z, Gyergyay F, Nagyiványi K, Géczi L.

Abiraterone acetate + prednisolone treatment beyond prostate specific antigen and radiographic progression in metastatic castration-resistant prostate cancer patients.

Urol Oncol. 2018 Feb;36(2):81.e1-81.e7.

IF:3.397

IV. Küronya Z, Bíró K, Géczi L, Maráz A.

Modern treatment of metastatic hormone-sensitive prostate cancer

Orv Hetil. 2018 Oct;159(41):1664-1671.

IF:0.322 


\section{List of publications related to the subject of the thesis}

V. Darr C, Krafft U, Hadaschik B, Tschirdewahn S, Sevcenco S, Csizmarik A, Nyirady P, Küronya Z, Reis H, Maj-Hes A, Shariat SF, Kramer G, Szarvas T.

The Role of YKL-40 in Predicting Resistance to Docetaxel Chemotherapy in Prostate Cancer. UROLOGIA INTERNATIONALIS 101: 1 pp. 65-73, 9 p. (2018)

VI. Maráz A, Boér K, Dankovics Z, Dank M, Lahm E, Petrányi Á, Révész J, Ruzsa Á, Szûcs M, Valikovics A, Vas M, Küronya Z.

Experience with cabazitaxel therapy for patients with metastatic castrate resistant prostate cancer in Hungary.

MAGYAR ONKOLÓGIA 61: 4 pp. 353-360., 8 p. (2017)

VII. Küronya Z, Géczi L, Gyergyay F, Bíró K.

The role of steroids in oncological practice.

ORVOSI HETILAP 158: 42 pp. 1651-1657., 7 p. (2017)

VIII. Küronya Z, Bíró K, Gyergyay F, Géczi L.

Androgen receptor-mediated processes in castrate-resistant metastatic prostate cancer.

ORVOSI HETILAP 158: 2 pp. 42-49., 8 p. (2017)

IX. Bíró, K ; Budai, B ; Szőnyi, M ; Bodrogi, I ; Küronya, Z ; Gyergyay, F ; Nagyiványi, $\mathrm{K}$; Géczi, L

Retrospective analysis of prognostic factors for survival in metastatic castration-resistant prostate cancer patients (mCRPC) treated with abiraterone

JOURNAL OF CLINICAL ONCOLOGY 34: Suppl p. e16504 (2016)

X. Küronya Z, Bíró K, Géczi L, Németh H.

Treatment strategies for advanced prostate cancer.

MAGYAR ONKOLÓGIA 59: 3 pp. 229-240. (2015) 


\section{Table of contents}

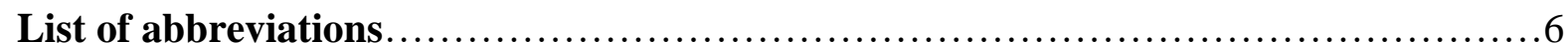

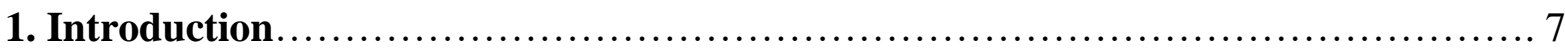

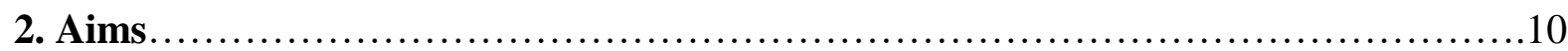

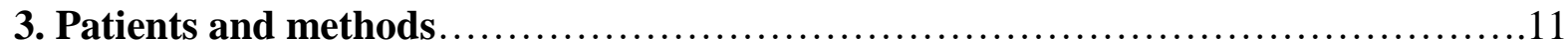

3.1. ERG Expression Can Predict the Outcome of Docetaxel Combined with Androgen Deprivation Therapy in Metastatic Hormone-Sensitive Prostate Cancer.....................11

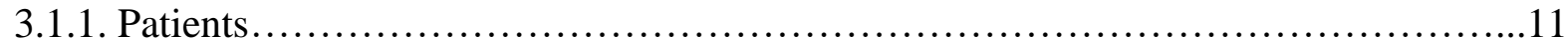

3.1.2. Methods..................................................................... 11

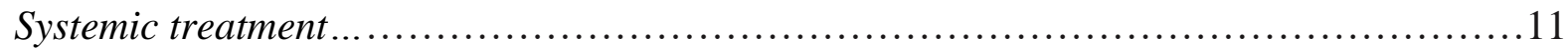

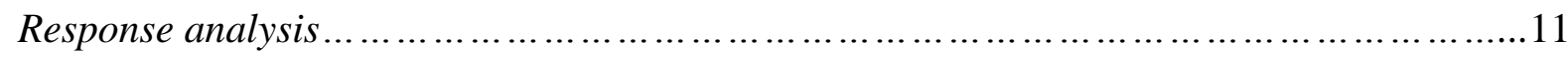

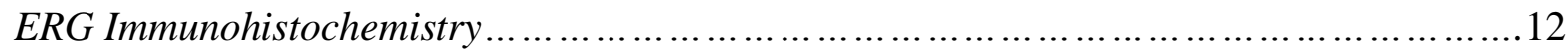

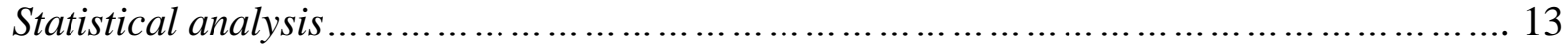

3.2. A Retrospective Analysis of the First $41 \mathrm{mCRPC}$ Patients with Bone Pain Treated with Radium-223 at the National Institute of Oncology in Hungary............................................14

3.2.1. Patients ...................................................................... 14

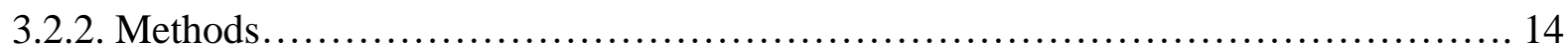

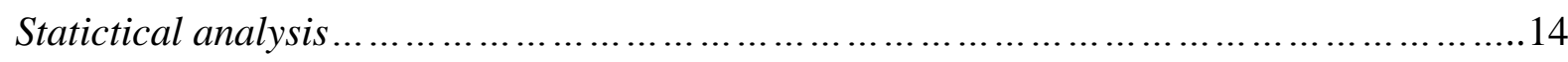

3.3. Abiraterone+prednisolone treatment beyond prostate specific antigen (PSA) and radiographic progression in metastatic castration-resistant prostate cancer patients $(m C R P C):$ a retrospective observational one-centre study ................................... 14

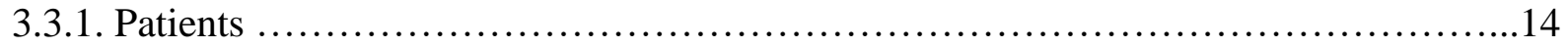

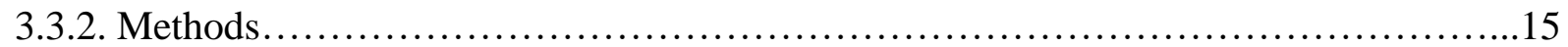

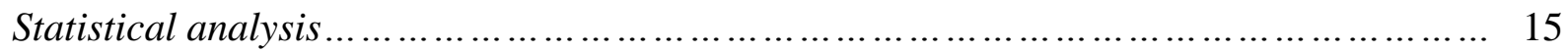

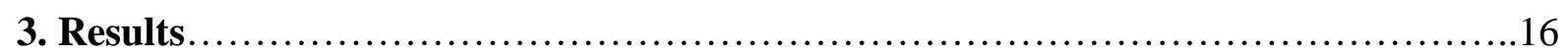

4.1.ERG Expression Can Predict the Outcome of Docetaxel Combined with Androgen

Deprivation Therapy in Metastatic Hormone-Sensitive Prostate Cancer ....................... 16

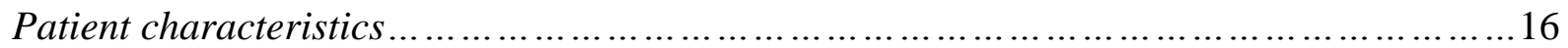

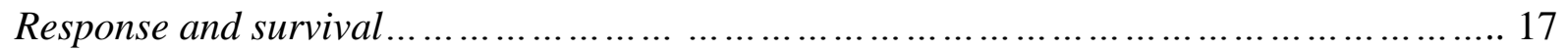

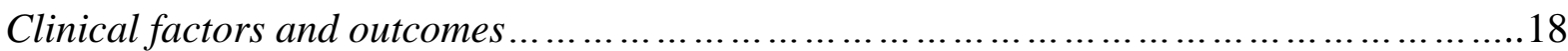

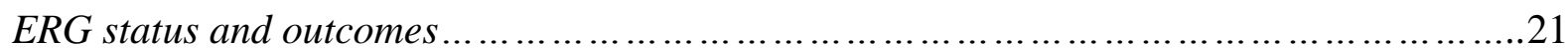

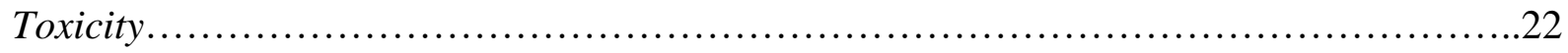


4.2. A Retrospective Analysis of the First 41 mCRPC Patients with Bone Pain Treated with Radium-223 at the National Institute of Oncology in Hungary.............................................23

4.2.1 .23

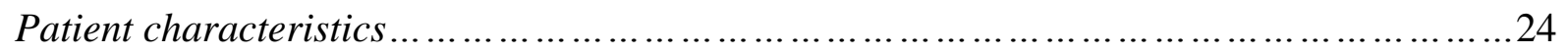

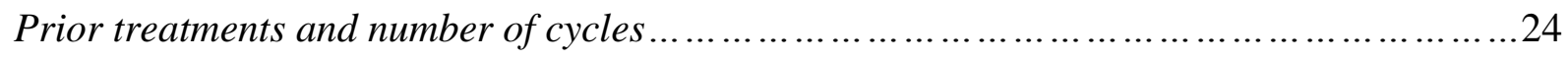

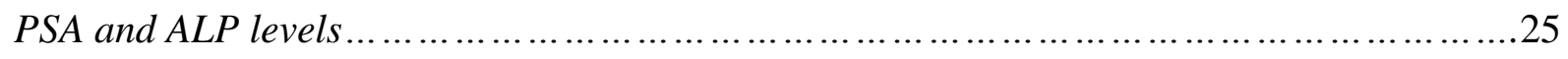

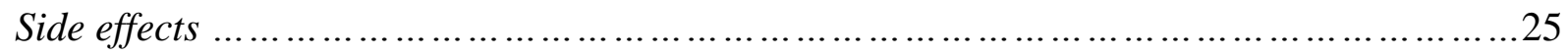

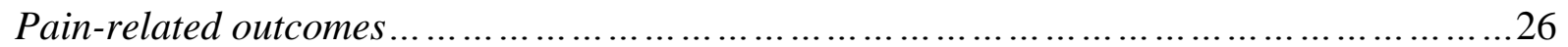

4.3. Abiraterone+prednisolone treatment beyond prostate specific antigen (PSA) and radiographic progression in metastatic castration-resistant prostate cancer patients $(m C R P C):$ a retrospective observational one-centre study ...................................28

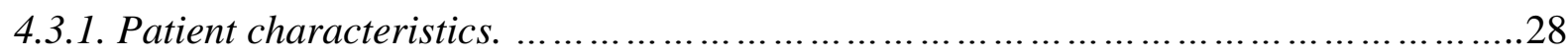

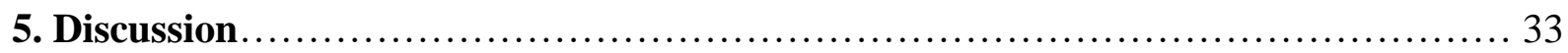

5.1 ERG Expression Can Predict the Outcome of Docetaxel Combined with Androgen

Deprivation Therapy in Metastatic Hormone-Sensitive Prostate Cancer.... .33

5.2. A Retrospective Analysis of the First $41 \mathrm{mCRPC}$ Patients with Bone Pain Treated with Radium-223 at the National Institute of Oncology in Hungary....

5.3. Abiraterone+prednisolone treatment beyond prostate specific antigen (PSA) and radiographic progression in metastatic castration-resistant prostate cancer patients

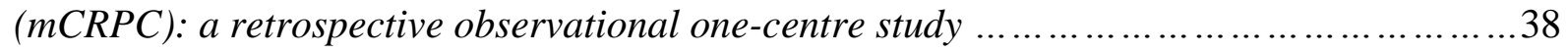

6. Summary, Conclusions ......................................................... 40

7. Acknowledgements.............................................................. 40

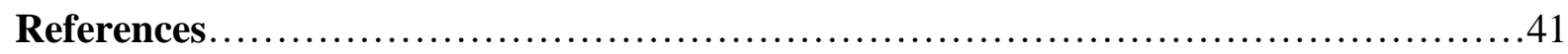

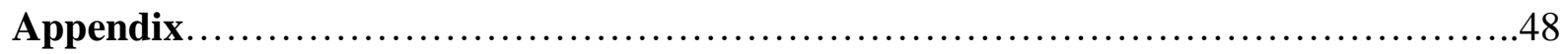




\section{List of abbreviations}

AA

ADT

AE

ALP

CHAARTED

ChT

CRPC

CTCAE

D

EAU

ECOG

EMA

ERG

FDA

GCSF

mCRPC

mHSPC

$\mathrm{N}$

OS

$\mathrm{P}$

PCWG2,3

PRP

PSA

RECIST

RFS

SRE

STAMPEDE

$\mathrm{T}$

WHO abiraterone

androgen deprivation therapy

Adverse Event

alkaline phosphatase

Chemo-Hormonal Therapy Versus Androgen Ablation Ramdomized

Trial for Extensive Disease in Prostate Cancer

chemotherapy

castration-resistant prostate cancer

Common Terminology Criteria for Adverse Events

docetaxel

European Association of Urology

Eastern Cooperative Oncology Group

European Medicines Agency

ETS-related gene

Food and Drug Administration

granulocyte colony stimulating factor

metastatic castration-resistant prostate cancer

metastatic hormone-sensitive prostate cancer

nonclinical trial group

overall survival

prednisolone

Prostate Cancer Working Group 2,3

radiographic progression

prostate-specific antigen

Response Evaluation Criteria in Solid Tumors

Relapse-free survival

skeletal related event

The Sytemic Therapy in Advancing or Metastatic Prostate Cancer:

Evaluation of Drug Efficacy

clinical trial patients

World Health Organization 


\section{Introduction}

Prostate cancer is the second most common malignant disease among men. Disease course shows great heterogeneity in terms of outcomes. During the past decade, significant advances have been made in the field of available treatment options. In the case of localised disease, modern radiotherapy and more and more effective surgical approaches have led to a further increase in survival rates. However, a significant proportion of patients progress despite the successful management of localised disease, and the presence of metastases is also common at the time of prostate cancer diagnosis.

The treatment of metastatic prostate cancer can be divided into hormone-sensitive and castration-resistant pathophysiological phases. Until recently, androgen deprivation therapy (ADT) alone by surgical or medical castration was the standard-of-care for metastatic hormone-sensitive prostate cancer (mHSPC) [1]. Once the disease progresses to castrationresistant prostate cancer (CRPC), currently approved therapeutic options include sipuleucel-T, enzalutamide, abiraterone, docetaxel, cabazitaxel, and Radium-223 [2,3].

Recently, there was a paradigm shift as a result of new data from clinical studies which opened new perspectives and changed the standard-of-care in mHSPC. In the pivotal CHAARTEED [4] and STAMPEDE-Docetaxel [5] studies, the combination of docetaxel and ADT demonstrated a survival benefit over ADT alone among patients with mHSPC. The randomized, phase III CHAARTED study was the first pivotal study to convincingly demonstrate the efficacy of early docetaxel among patients with mHSPC, particularly in the case of high-volume disease. Subsequently, STAMPEDE-Docetaxel, an ongoing, multi-arm trial investigating various therapeutic approaches in different stages of prostate cancer, confirmed the survival benefits of early docetaxel therapy seen in the CHAARTED study. As a result, early docetaxel is now recommended by all international guidelines as a part of standard therapy, and it is gradually being incorporated into Hungarian clinical practice, as well. Similarly, early abiraterone therapy was also integrated into the standard-of-care in combination with ADT among patients with newly-diagnosed, high-risk mHSPC due to the favorable results of the multinational, randomized, placebo-controlled phase III LATITUDE clinical trial [6], and the STAMPEDE-Abiraterone study [7]. Based on the available evidence, the decision-making process during the management of patients with $\mathrm{mHSPC}$ should involve the determination of disease volume as well as the assessment of individual risk, 
comorbidities, toxicity, and patient preference. In the case of high-volume disease, ADT and docetaxel or (if Gleason score $\geq 8$ ) abiraterone, or ADT alone is recommended, while for patients with low-volume disease, ADT monotherapy or - in high-risk patients - ADT in combination with abiraterone should be administered [8]. Therefore, in many cases, clinicals are faced with the dilemma of choosing between docetaxel (D) and abiraterone (AA), especially among patients with a high burden of mHSPC.

The identification of biomarkers which are potentially associated with response to therapy and clinical outcomes remains to be a major unmet need both in the hormone-sensitive and castration-resistant phases. During the previous years, several retrospective studies focused on the identification of factors with potential predictive value in prostate cancer with a view to help identify baseline resistance to D or AA and optimize treatment decisions [9-11]. One of the genetic alterations which have been implicated in the development of taxane-resistance is the overexpression of ERG (ETS-related gene), a member of the ETS transcription factor family, which results from recurrent gene fusions with an androgen-regulated 5' gene partner, TMPRSS2 [12-14]. The TMPRSS2: ERG fusion gene is the most common ETS gene rearrangement in prostate cancer which can be detected in about 50\% of patients [12]. Interestingly, Galletti et al. demonstrated that ERG overexpression was associated with decreased sensitivity to taxanes in in vitro and in vivo models of CRPC [15].

Therefore, the identification of ERG status may allow for a tailored approach and may help predict response to docetaxel chemotherapy (ChT) as well as clinical outcomes. While these studies provide valuable information, which may aid treatment decisions and patient selection for appropriate therapies, most of them focused on the predictive value of the examined factors in the castration-resistant phase. Consequently, it is not yet understood whether the biomarkers implicated in mCRPC might have a predictive value in the hormone-sensitive phase regarding response to early D therapy added to ADT.

CRPC is defined by disease progression despite ADT, and may manifest as either a continuous rise in serum prostate-specific antigen (PSA) levels, the progression of preexisting disease, and/or the appearance of new metastases [16]. Metastatic CRPC (mCRPC) frequently metastasizes to the bone, often resulting in painful skeletal events, reduced quality of life, and reduced survival [17,18]. Previous studies have shown that as prostate cancer transitions from castration sensitive to castration resistant, the incidence of bone metastasis increases, and eventually more than $90 \%$ of patients with mCRPC develop bone metastases 
[19]. Patients with mCRPC and bone metastases often experience skeletal-related events (SREs) such as pathologic fractures and spinal cord compression, which are major causes of morbidity and can lead to other comorbidities [20]. Skeletal complications due to bone metastases are strong determinants of quality of life and survival in these patients [21]. Traditionally, the treatment strategies of bone metastases in patients with mCRPC were aimed at managing pain and reducing skeletal complications [22]. However, ongoing research led to the development of targeted therapeutics, such as the radiopharmaceutical Radium-223 dichloride (Radium-223, Xofigo ${ }^{\circledR}$ ). Radium-223 is a calcium-mimetic alpha-emitting radiopharmaceutical, which selectively targets bone, specifically the areas of bone metastases, while sparing normal tissue [23,24]. Alpha particles travel much shorter distances than beta particles, and are therefore less damaging to normal tissue, which explains the fewer sideeffects observed with Radium-223 therapy compared to beta-emitting radiopharmaceuticals [25-32]. Unlike previous radiopharmaceuticals, Radium-223 was found to prolong survival in patients with mCRPC in the pivotal phase III ALSYMPCA trial [33]. Based on the results of this study, Radium-223 was approved by the FDA (Food and Drug Administration) in May 2013 for the treatment of patients with CRPC, symptomatic bone metastases and no known visceral metastatic disease, which was followed by the granting of marketing authorization in Europe by the European Commission in November, 2013. The approved dosing of Radium223 is $50 \mathrm{kBq} / \mathrm{kg}$ given intravenously over 1 minute every 28 days for 6 doses [34]. Radium223 has been reimbursed in Hungary since July 2014 on an individual basis. The National Healthcare System covers the medicine for patients with progressive mCRPC and bone pain, at least two bone metastases detected on skeletal scintigraphy, lymph nodes with a maximum size of $3 \mathrm{~cm}$, and no known visceral metastasis.

Apart from Radium-223, currently available agents for mCRPC in the post-docetaxel setting include cabazitaxel, enzalutamide and abiraterone, while the options for prechemotherapy treatment are enzalutamide and abiraterone. As mentioned before, the indication for abiraterone was recently expanded. Since 2017, abiraterone is also approved for the treatment of newly diagnosed, high-risk mHSPC patients, which led to significant changes in the recommended therapeutic sequences in mCRPC. Consequently, clinicians are faced with the growing challenge of providing a tailored approach. Ideally, patients should be provided with the benefits of all treatment lines while achieving the best possible quality of life, which requires the appropriate assessment of progression in all disease stages and during all treatment regimens. 
In the TAX 327 clinical study with docetaxel, radiographic progression was assessed using WHO (World Health Organization) criteria, while the cabazitaxel registration trial already applied the RECIST (Response Evaluation Criteria in Solid Tumors) 1.1 criteria. In studies testing abiraterone/enzalutamide in the prechemotherapy setting, progression was evaluated according to Prostate Cancer Clinical Trials Working Group 2 (PCWG2) [35] recommendations. The most important learning point from the PCWG2 consensus is that PSA progression in itself without radiographic or clinical progression should not be regarded as an indication for treatment discontinuation. Since 2016, newly designed clinical studies routinely apply the PCWG3[36] criteria. The PCW3G consensus underlines the importance of documenting progression as distinct from the decision to terminate treatment, keeping in mind the biological heterogeneity of individual metastatic lesions. PCWG3 introduced the concept of „no longer clinically benefitting” (NLCB) in order to avoid the premature or undue discontinuation of treatment. The new guidelines highlight the need for documenting the exact time and reason for treatment discontinuation, and allow for individual decisions on treatment continuation in the case of radiographic or biochemical progression if there are perceived additional benefits to slowing progression in patients without clinical progression.

\section{Aims}

The primary objective of this thesis was to identify management strategies that may improve quality of life and overall survival and facilitate individualized treatment approaches for patients with metastatic prostate cancer. In details:

2.1. Our study aimed to analyze the potential association between clinical parameters and ERG expression and the outcome of docetaxel chemotherapy among patients with mHSPC.

2.2. Our specific aim was to investigate the efficacy and safety of Radium-223, and to assess the changes in pain intensity as a result of Radium-223 therapy.

2.3. To investigate the overall survival (OS) of chemotherapy refractory mCRPC patients who were treated with abiraterone acetate + prednisolone $(\mathrm{AA}+\mathrm{P})$ beyond PSA and radiographic progression (PRP) until clinical progression in comparison to patients treated only until PRP. 


\section{Patients and methods}

\subsection{ERG Expression Can Predict the Outcome of Docetaxel Combined with Androgen Deprivation Therapy in Metastatic Hormone-Sensitive Prostate Cancer}

\subsubsection{Patients}

Potentially eligible cases were identified from a patient database with mHSPC receiving docetaxel ChT for mHSPC between 1 August 2014 and 31 October 2017 at one of the two centers, the National Institute of Oncology, Budapest and the Department of Oncotherapy, University of Szeged. Patients were included in the study if they had paraffin tissue blocks from diagnostic samples or metastatic sites. All tumors were objectively confirmed by histological verification, and staging procedures as well as ADT were carried out according to the conventional protocol. For each patient, treatment plan was designed by a multidisciplinary tumor board.

\subsubsection{Methods}

Systemic treatment. All patients received intravenous docetaxel ChT (docetaxel every 3 weeks at a dose of $75 \mathrm{mg} / \mathrm{m}^{2}$ in 6 cycles depending on toxicity, without prednisone), starting within 120 days after the initiation of ADT. All patients signed a written informed consent prior to the initiation of chemotherapy. The use of prophylactic granulocyte colony stimulating factor (GCSF) was allowed. Dose reduction or delay was performed at the oncologist's discretion. Physical examination and laboratory tests were carried out every 3 weeks. The severity of AEs (Adverse Events) was evaluated based on the National Cancer Institute Common Terminology Criteria for Adverse Events, Version 4.0 [37]. Patients' general condition was assessed using the ECOG (Eastern Cooperative Oncology Group) scale [38]. Data were collected prospectively starting in August 2014.

Response analysis. The assessment of outcomes was carried out before and 8-12 weeks after the completion of chemotherapy and involved clinical examinations, PSA measurements, bone scan, and diagnostic chest-abdomino-pelvic CT examinations. Response to therapy and follow-up were assessed according to the PCWG2 criteria system [35]. Good response was 
defined as a $\geq 50 \%$ decrease in baseline PSA levels. Relapse-free survival (RFS) and overall survival (OS) were defined as the period from the initiation of ChT to the detection of castration-resistant prostate cancer or death [39]. Early progression was defined as the development of CRPC within 12 months after the initiation of ChT.

ERG Immunohistochemistry. Prostate cancer tissue samples were obtained from needle biopsies, transurethral resections of the prostate, prostatectomies, or prostate cancer metastases (one pulmonary and one lymph node metastasis). Before ChT, immunhistochemical (IHC) staining was performed to quantify ERG expression in the biopsy samples. Histological samples were obtained from different pathological departments where primary diagnoses were made. Prostate biopsy tissue samples were examined in a retrospective way with regards to ERG expression at the Department of Pathology, University of Szeged.

The following primary mouse monoclonal antibody was used for IHC: ERG (clone EP 111, Cell Marque \# 434R-14) was diluted at 1:500. Deparaffinization and rehydration at room temperature were followed by antigen retrieval with the PT Link system (10 mM sodium citrate buffer, $\mathrm{pH}$ 6.0, for $30 \mathrm{~min}$ at $94^{\circ} \mathrm{C}$; Dako, Glostrup, Denmark). After rinsing with Trisbuffered saline (EnVision FLEX Wash), the sections were placed in a Dako Autostainer Link 48 for endogenous peroxidase blockage and staining. Diaminobenzidine was used as chromogen. The sections were then counterstained with Mayer's hematoxylin, dehydrated, cleared in xylene and mounted. Negative controls were obtained by the omission of the primary antibody. The positive controls for ERG were endothelial cells. Only subjects with nuclear ERG immunoreactivity were classified as ERG positive [40] (Figure 1). For the main analysis of ERG expression in relation to prostate cancer mortality, we used a dichotomous marker cut point (positive or negative for nuclear ERG immunoreactivity). 


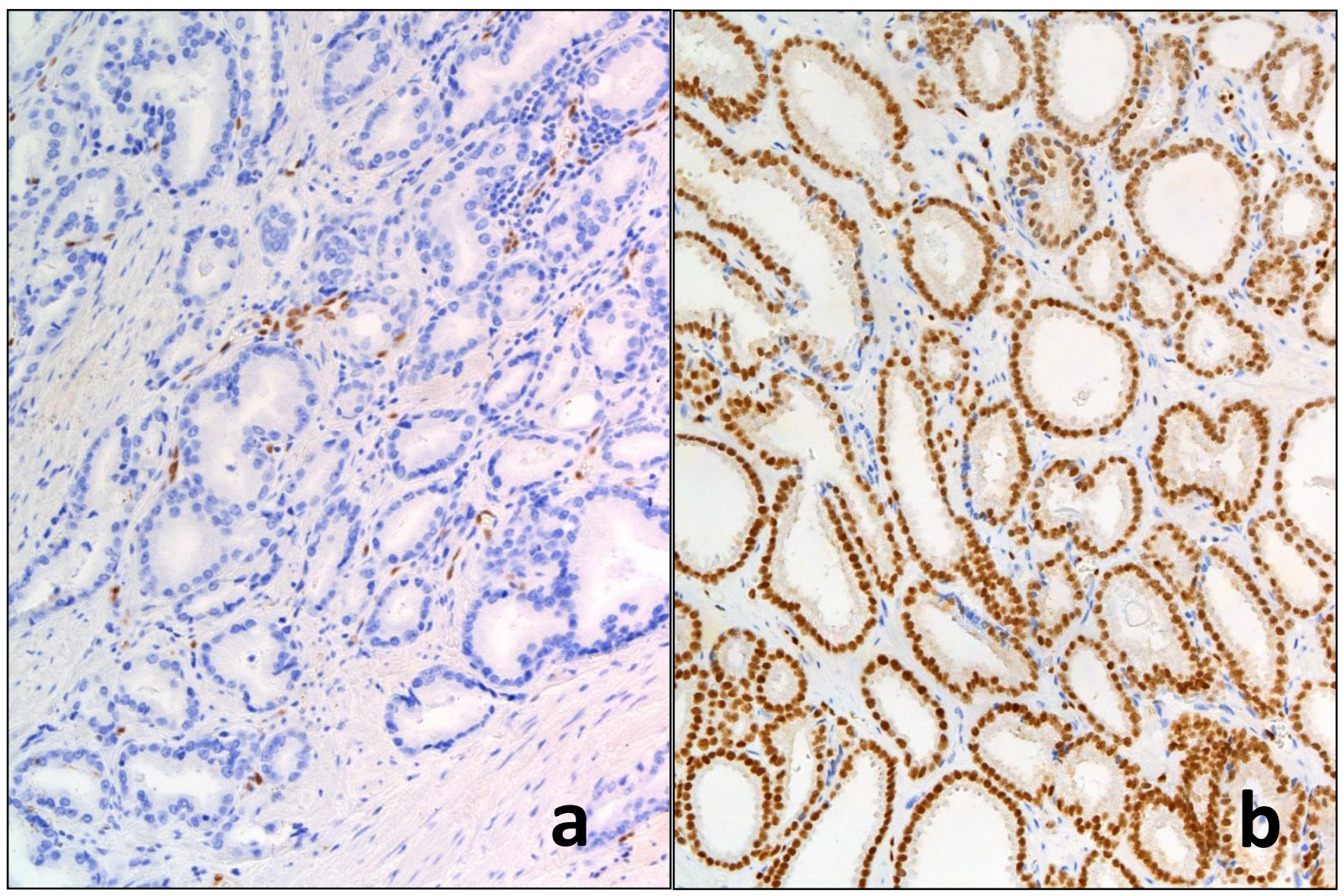

Fig 1. Immunohistochemistry: prostate cancer stained with ERG antibody. Brown tumor cell nuclei represent ERG positivity. a) ERG negative prostate cancer. The endothelial cells serve as internal positive controls. b) ERG positive prostate cancer. The glandular cells of adenocarcinoma are strongly ERG positive.

Statistical analysis. The association between patient characteristics and RFS or OS were analyzed by Kaplan-Meier analysis for categorical variables and by Cox regression for continuous variables. To detect the joint effect of the decrease in PSA level and ERG expression on RFS, multivariate Cox regression analysis (forward likelihood ratio method) was applied. All statistical analyses were performed using the IBM SPSS v22.0 software (IBM Corp. Released 2013. IBM SPSS Statistics for Windows, Version 22.0. Armonk, NY: IBM Corp). 
3.2. A Retrospective Analysis of the First 41 mCRPC Patients with Bone Pain Treated with Radium-223 at the National Institute of Oncology in Hungary.

\subsubsection{Patients}

This was a single-center retrospective study carried out at the National Institute of Oncology, Budapest, Hungary. All mCRPC patients receiving Radium-223 for the treatment of bone metastases between $23^{\text {rd }}$ July 2014 and $23^{\text {rd }}$ February 2016 were included in the analysis.

\subsubsection{Methods}

Informed consent was obtained from all individual participants included in the study. Patients were administered intravenous Radium-223 at a dose of $50 \mathrm{kBq} / \mathrm{kg}$ over one minute every 28 days for up to 6 cycles. Medical records were reviewed for patient demographics and baseline characteristics, laboratory PSA and alkaline phosphatase (ALP) values, treatment outcomes, treatment-emergent adverse events, and changes in pain intensity. The patients' level of functioning was assessed by the ECOG Scale of Performance Status before Radium-223 treatment. Pain intensity was subjectively assessed, and changes in bone pain were classified as 'increase', 'no change', 'decrease', or 'complete cessation'.

Statictical analysis. Data were assessed using descriptive statistics in SPSS 17.0. In accordance with the ALSYMPCA trial, imaging tests were not routinely performed during Radium-223 therapy, unless there was a clinical indication.

3.3. Abiraterone+prednisolone treatment beyond prostate specific antigen (PSA) and radiographic progression in metastatic castration-resistant prostate cancer patients ( $m C R P C)$ : a retrospective observational one-centre study

\subsubsection{Patients}

Unselected cohorts of mCRPC patients treated at the National Institute of Oncology were investigated. The first AA+P treatment started on April 21, 2011 in an early-access protocol trial (NCT01217697). After October 8, 2012 AA became generally available in Hungary. It has been reimbursed based on special request on an individual basis. 
From April 21, 2011 to November 05, 2014116 patient received AA+P. All patients progressed during or after docetaxel treatment. $\mathrm{AA}+\mathrm{P}$ was administered according to the treatment protocol including 1,000 mg AA and $10 \mathrm{mg} P$ daily. All patients had ECOG 0 or 1 performance status. The clinical trial patients $(T)(n=56)$ were treated beyond PRP until clinical progression.

\subsubsection{Methods}

Definition of clinical progression at the early access protocol (EAP) ${ }^{12}$ program was either pain progression (e.g. an opiate was needed for $>2$ weeks), development of a skeletal-related event (e.g. pathological fracture, spinal-cord compression, or surgery to bone); any increase in dose of prednisolone or a change to a more potent glucocorticoid for prostate cancer-related signs and symptoms; or initiation of new systemic anticancer treatment. In the nonclinical trial group $(N)(n=57)$ the treatment was covered only until PRP. During the follow-up 3 patients remained PRP-free, thus were excluded from further analyses. Laboratory parameters and side effects were assessed every 4 weeks, efficacy (CT, bone scan, PSA) at three-month intervals. Treatment outcomes and adverse events were retrospectively evaluated from patient's charts. The study was approved by the Medical Research Council and the Ethical Committee of the Institute.

Statistical analysis. OS, as primary objective of this study, was evaluated by Kaplan Meier method and log rank test was performed. The secondary objective was PRP-free survival. The median or mean levels were compared by t-test or Mann-Whitney nonparametric test as required. The difference in distribution of parameters was tested by chi2 or exact test. Multivariate logistic regression was also performed. In order to find independent markers of survival the multivariate Cox regression analysis was used. $\mathrm{P}<0.05$ was considered as statistically significant. The NCSS software (Kaysville, UT, USA) was used for all statistical analyses. 


\section{Results}

\subsection{ERG Expression Can Predict the Outcome of Docetaxel Combined with Androgen Deprivation Therapy in Metastatic Hormone-Sensitive Prostate Cancer}

Patient characteristics. Altogether 55 patients were included in the study, with a mean age of $65.6 \pm 1.1$ years (range: 43-79). Most patients (94.5\%) had high-volume disease, defined as the presence of visceral metastases and/or $\geq 4$ bone metastases with at least one outside the vertebral column and pelvis (CHAARTED study definition) [4]. Most of the patients also had a Gleason score of $\geq 8$, with a mean value of $8.67 \pm 0.14$. Performance status was generally good (ECOG 0: 67.3\%; ECOG 1: 27.3\%), ECOG 2 status was detected in only 3 cases (5.5\%). At the time of diagnosis, the mean PSA level of patients was $629.6 \pm 161.7 \mathrm{ng} / \mathrm{ml}$. The histological type of prostate cancer was adenocarcinoma in all cases; 2 patients had previously undergone radical prostatectomy [Table 1].

\begin{tabular}{|c|c|c|c|}
\hline \multicolumn{2}{|l|}{$\mathrm{N}=55$} & \multicolumn{2}{|c|}{ Patients } \\
\hline \multicolumn{2}{|l|}{ Mean age, years \pm SE } & \multicolumn{2}{|c|}{$65.6 \pm 1.1$} \\
\hline \multicolumn{2}{|l|}{ Age range, years } & \multicolumn{2}{|c|}{$43-79$} \\
\hline \multicolumn{2}{|l|}{ Gleason score, mean $\pm \mathrm{SE}$} & \multicolumn{2}{|c|}{$8.67 \pm 0.14$} \\
\hline \multicolumn{2}{|l|}{ Initial PSA, mean $\pm \mathrm{SE}$} & \multicolumn{2}{|c|}{$629.6 \pm 161.7$} \\
\hline & & $\mathrm{n}$ & $\%$ \\
\hline \multirow[t]{3}{*}{ ECOG performance status } & 0 & 37 & 67.3 \\
\hline & 1 & 15 & 27.3 \\
\hline & 2 & 3 & 5.5 \\
\hline \multirow[t]{2}{*}{ Volume of disease } & high & 52 & 94.5 \\
\hline & low & 3 & 5.5 \\
\hline \multicolumn{4}{|l|}{ Location of Metastases } \\
\hline \multicolumn{2}{|l|}{ Bone } & 50 & 90.9 \\
\hline \multicolumn{2}{|l|}{ Distant lymph node } & 32 & 58.2 \\
\hline \multicolumn{2}{|l|}{ Visceral } & 13 & 23.6 \\
\hline \multirow[t]{2}{*}{ Number of involved organs } & One & 21 & 38.2 \\
\hline & More & 34 & 61.8 \\
\hline
\end{tabular}

Table 1: Patient characteristics. ECOG: Eastern Cooperative Oncology Group; n: number of patients included; N: number of patients analyzed; SE: standard error; PSA: prostate-specific antigen. 
Response and survival. The mean time between the initiation of ADT and docetaxel ChT was $73.9 \pm 3.9$ days. The mean number of docetaxel cycles received by patients was $5.69 \pm 0.17$.

Overall, RFS and OS were 10.5 \pm 3.2 months and $40.4 \pm 8.9$ months, respectively. By the time of study completion, 17 patients had died (30.9\%), 14 of which due to prostate cancer, 2 due to the development of pneumonia or ileus after ChT, and 1 due to subsequently detected advanced colorectal cancer. Disease progression was mostly detected with increasing PSA levels in 31 patients (56.4\%), out of which 19 (34.5\%) were bone, 8 (14.5\%) were visceral, and $4(7.3 \%)$ were distant lymph node metastases. Castration-resistant prostate cancer developed in 32 patients (58.2\%), out of which 23 cases ( $41.8 \%$ of all patients) were detected within 12 months from the initiation of docetaxel ChT. The mean OS after the development of castration-resistant status was 17.2 \pm 5.4 months. PSA decrease was detected in 51 cases (92.7\%), the mean rate of decrease was $84.7 \pm 4.1 \mathrm{ng} / \mathrm{ml}$. The nadir PSA level was $34.0 \pm 19.8$ $\mathrm{ng} / \mathrm{ml}$, a reduction of at least $50 \%$ was detected in 44 patients $(80 \%)$ [Table 2].

\begin{tabular}{|l|l|l|}
\hline N=55 \\
\hline Mean time from ADT to ChT, days \pm SE & $73.9 \pm 3.9$ \\
\hline Number of ChT cycles, mean \pm SE & $5.69 \pm 0.17$ \\
\hline PSA response & $34.0 \pm 19.8$ \\
\hline Nadir PSA level, mean ng/ml \pm SE & $51(92.7 \%)$ \\
\hline Number of pts with PSA decrease & $84.7 \pm 4.1$ \\
\hline PSA decrease rate, mean \% \pm SE & $44(80 \%)$ \\
\hline Number of pts with $\geq 50 \%$ PSA decrease & \multicolumn{2}{|l|}{} \\
\hline CRPC after ChT & $32(58.2 \%)$ \\
\hline Number of pts with CRPC after ChT & $15.6(95 \%$ CI 10.6-20.6) \\
\hline Median RFS to CRPC, months & $\boldsymbol{n}$ & $\%$ \\
\hline Location of progression & 31 & 56.4 \\
\hline PSA & 19 & 34.5 \\
\hline Bone & 4 & 7.3 \\
\hline Distant lymph node & 8 & 14.5 \\
\hline Visceral & \multicolumn{2}{|l|}{} \\
\hline
\end{tabular}




\begin{tabular}{|l|l|l|l|}
\hline \multirow{3}{*}{ Site of progression } & Only PSA & 23 & 41.8 \\
\cline { 2 - 4 } & One organ & 5 & 9.1 \\
\cline { 2 - 4 } & More organs & 27 & 49.1 \\
\hline Subsequent therapies & Abiraterone & 19 & 34.5 \\
\hline & Enzalutamide & 4 & 7.3 \\
\hline & Alfaradine & 4 & 7.3 \\
\hline & Cabazitaxel & 3 & 5.5 \\
\hline & Docetaxel & 1 & 1.8 \\
\hline OS from ChT, median, months & $40.4(95 \%$ CI 22.9-57.9) \\
\hline OS from date of CRPC, median, months & $17.2(95 \%$ CI 6.7-27.8) \\
\hline
\end{tabular}

Table 2: Parameters of chemotherapy and clinical outcomes. ADT: androgen deprivation therapy; ChT: chemotherapy; CRPC: castration-resistant prostate cancer, N: number of patients analyzed; OS: overall survival; SE: standard error; PSA: prostate-specific antigen; pts: patients; RFS: relapse-free survival.

Clinical factors and outcomes. There was no significant association between RFS/OS and age, Gleason score, initial PSA level, the type of involved organs, or the number of docetaxel cycles. Performance status was significantly associated with clinical outcomes: patients with an ECOG status of 0 had a mean RFS of $17.9 \pm 4.6$ and a mean OS of $40.43 \pm 9.4$; those with an ECOG status of 1 had a mean RFS of $8.9 \pm 2.1$ and a mean OS of $25.7 \pm 3.7$, while an ECOG status of 2 was associated with a mean RFS of $9.1 \pm 6.6$ and a mean OS of 10.2 \pm 7.5 .

There were significant differences in RFS and OS between patients with a good PSA response (defined as a $\geq 50 \%$ decrease in PSA level) and those without (RFS: $16.8 \pm 2.3 v s$. $5.9 \pm 0.1$ months, $\mathrm{p}<0.001$; OS: $40.4 \pm 12.2$ vs. $11.6 \pm 0.8$ months, $\mathrm{p}<0.001$ ) [Figure 2, Figure 3]. Merely biochemical or oligoprogression were associated with better RFS and OS compared to progression to multiple organs (RFS: $40.2 \pm 2.8$ vs. $10.8 \pm 0.9$ months, $\mathrm{p}<0.001$; OS: $40.4 \pm 8.9$ vs. $23.6 \pm 2.9$ months, $\mathrm{p}=0.011$ ). Progression within 12 months from the initiation of docetaxel ChT was associated with poorer OS compared to progression after 12 months $(17.97 \pm 7.6$ months vs 40.4 \pm 8.9 months, $\mathrm{p}<0.001$ ) [Table 3]. 


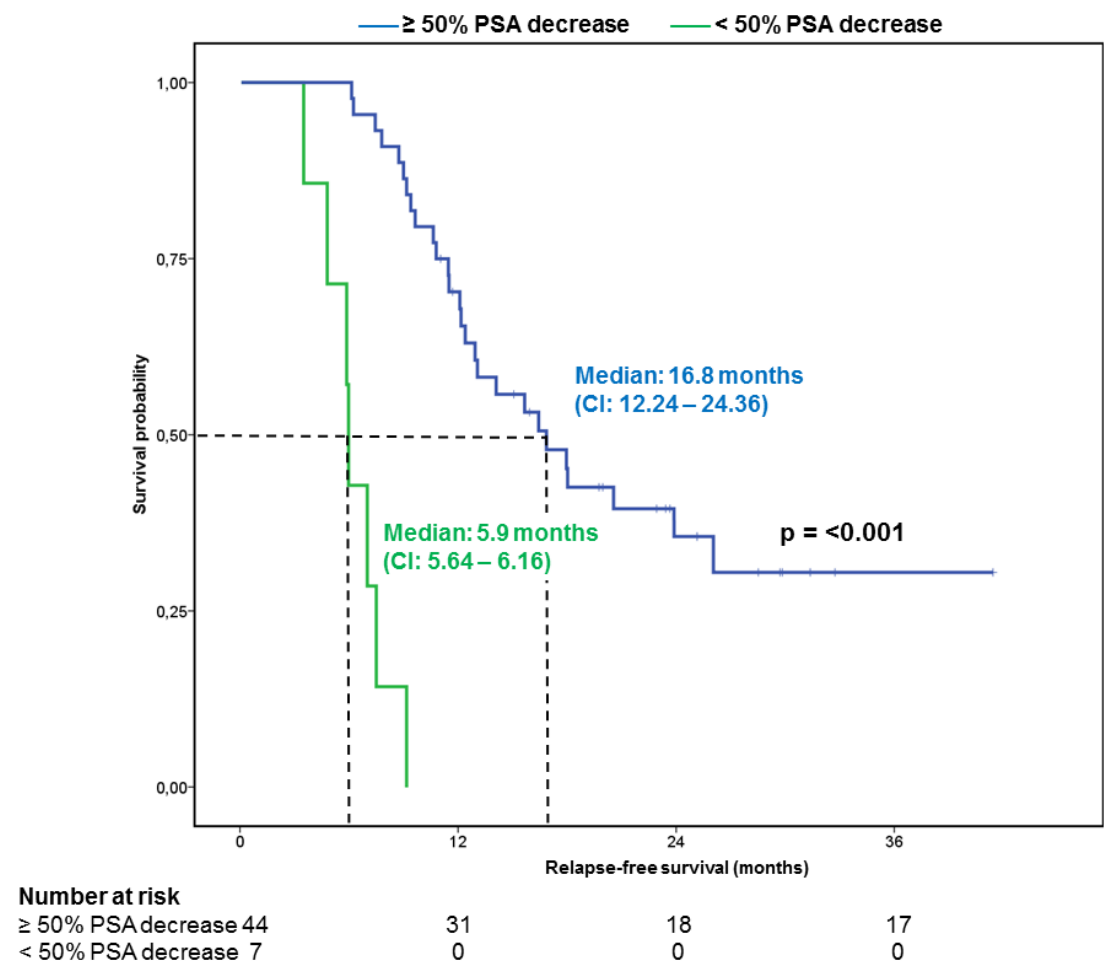

Figure 2: RFS as a function of PSA decrease. CI: confidence interval; PSA: prostate-specific antigen.

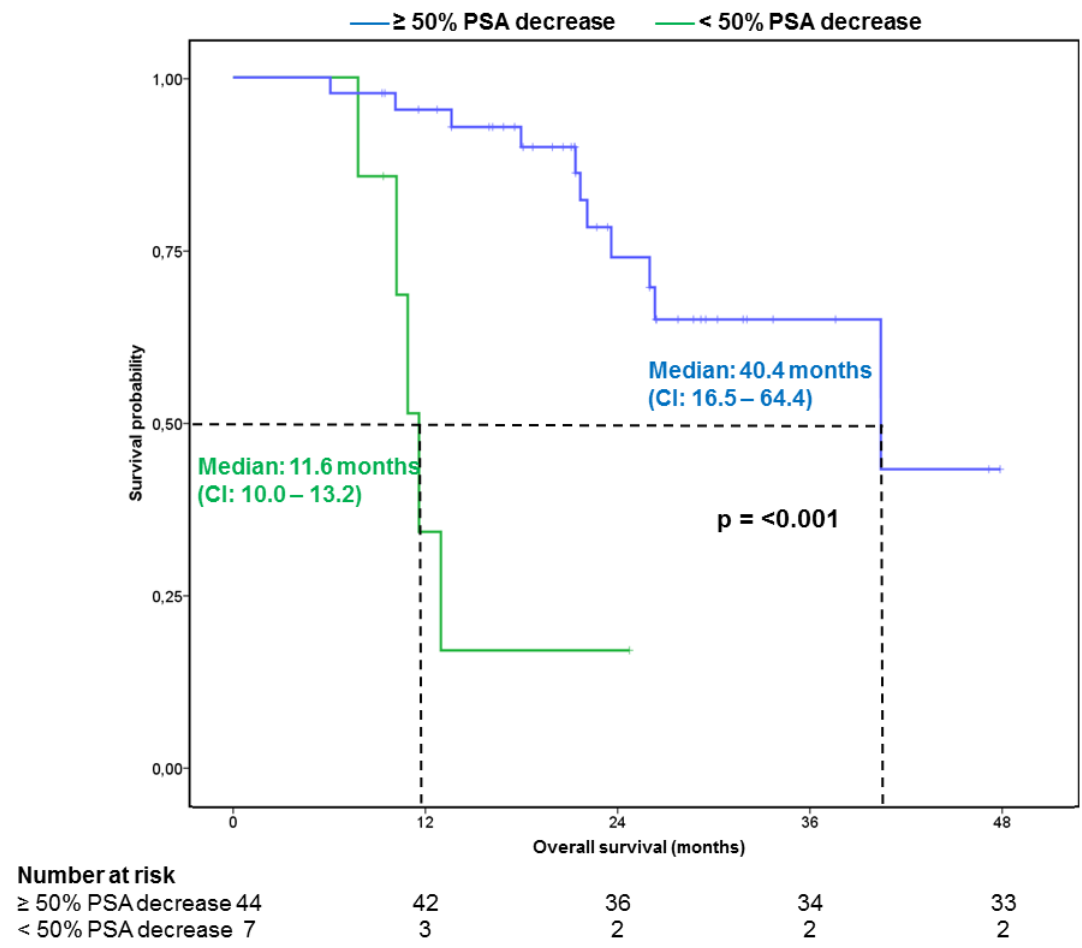

Figure 3: OS as a function of PSA decrease. CI: confidence interval; PSA: prostate-specific antigen. 


\begin{tabular}{|c|c|c|c|c|c|c|}
\hline \multicolumn{3}{|c|}{$\begin{array}{l}\text { Specifications of analyzed } \\
\text { patients } N=55\end{array}$} & RFS-HR (95\% CI) & $p$ & OS-HR (95\% CI) & $p$ \\
\hline \multicolumn{3}{|l|}{ Age } & $0.988(0.947-1.031)$ & 0.592 & $\begin{array}{c}1.018(0.960- \\
1.079)\end{array}$ & 0.553 \\
\hline \multicolumn{3}{|c|}{ Gleason score } & $1.405(0.908-2.174)$ & 0.127 & $\begin{array}{c}1.425(0.773- \\
2.627)\end{array}$ & 0.256 \\
\hline \multicolumn{3}{|c|}{ Initial PSA level (ng/ml) } & $1.000(0.999-1.000)$ & 0.264 & $\begin{array}{c}0.999(0.997- \\
1.000)\end{array}$ & 0.093 \\
\hline \multicolumn{3}{|c|}{ Level of PSA nadir (ng/ml) } & $1.010(0.999-1.021)$ & 0.085 & $\begin{array}{c}0.999(0.995- \\
1.004)\end{array}$ & 0.728 \\
\hline \multicolumn{3}{|c|}{ Rate of PSA decrease (\%) } & $0.964(0.950-0.978)$ & $<0.001$ & $\begin{array}{c}0.979(0.966- \\
0.992)\end{array}$ & 0.001 \\
\hline \multicolumn{3}{|c|}{ Number of ChT cycles } & $1.231(0.809-1.873)$ & 0.332 & $\begin{array}{c}0.910(0.646- \\
1.281)\end{array}$ & 0.589 \\
\hline & & & $\mathbf{m R F S} \pm \mathrm{SE}$ (months) & $p$ & $\mathbf{m O S} \pm \mathrm{SE}$ (months) & $p$ \\
\hline \multicolumn{2}{|c|}{$\begin{array}{l}\text { Pts with } \geq 50 \% \text { PSA } \\
\text { decrease }\end{array}$} & No / Yes & $5.9 \pm 0.13 / 16.8 \pm 2.3$ & $<0.001$ & $\begin{array}{l}11.6 \pm 0.8 / \\
40.4 \pm 12.2\end{array}$ & $<0.001$ \\
\hline \multicolumn{2}{|c|}{ ECOG status } & $0 / 1 / 2$ & $\begin{array}{c}17.9 \pm 4.6 / 8.9 \pm 2.1 / \\
9.1 \pm 6.6\end{array}$ & 0.002 & $\begin{array}{c}40.4 \pm 9.4 / 25.7 \pm 3.7 \\
/ 10.2 \pm 7.5\end{array}$ & 0.002 \\
\hline \multicolumn{2}{|c|}{ Extension of volume } & $\begin{array}{l}\text { High / } \\
\text { Low }\end{array}$ & $12.8 \pm 1.2 / 16.8 \pm 2.4$ & 0.944 & $30.5 \pm 8.7 / 40.8 \pm 8.9$ & 0.475 \\
\hline \multirow{3}{*}{$\begin{array}{l}\text { Locatio } \\
\mathrm{n} \text { of } \\
\text { metas- } \\
\text { tases }\end{array}$} & Bone & No / Yes & $18.9 \pm 2.3 / 25.6 \pm 2.4$ & 0.711 & $22.5 \pm 6.3 / 33.5 \pm 2.7$ & 0.368 \\
\hline & $\begin{array}{l}\text { Lymph } \\
\text { node }\end{array}$ & No / Yes & $26.7 \pm 3.1 / 23.9 \pm 2.9$ & 0.354 & $38.5 \pm 3.7 / 29.2 \pm 2.5$ & 0.307 \\
\hline & Visceral & No / Yes & $27.3 \pm 2.7 / 17.2 \pm 2.5$ & 0.188 & $32.6 \pm 2.8 / 34.3 \pm 5.3$ & 0.932 \\
\hline \multicolumn{2}{|c|}{$\begin{array}{l}\text { Number of involved } \\
\text { organs }\end{array}$} & $1 /$ More & $28.5 \pm 3.2 / 22.8 \pm 2.7$ & 0.111 & $42.1 \pm 3.0 / 29.0 \pm 2.9$ & 0.066 \\
\hline Locatio & PSA & No / Yes & $45.3 \pm 1.7 / 11.4 \pm 0.8$ & $<0.001$ & $30.5 \pm 3.2 /$ & 0.323 \\
\hline
\end{tabular}




\begin{tabular}{|c|c|c|c|c|c|c|}
\hline \multirow{4}{*}{$\begin{array}{l}\mathrm{n} \text { of } \\
\text { prog- } \\
\text { ression }\end{array}$} & & & & & $40.4 \pm 11.6$ & \\
\hline & Bone & No / Yes & $33.2 \pm 3.1 / 11.2 \pm 1.2$ & $<0.001$ & $37.4 \pm 3.2 / 26.6 \pm 3.1$ & 0.043 \\
\hline & $\begin{array}{l}\text { Lymph } \\
\text { node }\end{array}$ & No / Yes & $17.9 \pm 2.8 / 5.9 \pm 2.8$ & 0.002 & $40.4 \pm 7.5 / 10.9 \pm 3.2$ & 0.158 \\
\hline & Visceral & No / Yes & $20.5 \pm 4.8 / 7.4 \pm 0.4$ & $<0.001$ & $\begin{array}{c}40.4 \pm 8.9 / 11.6 \\
\pm 1.8\end{array}$ & $<0.001$ \\
\hline \multicolumn{2}{|c|}{$\begin{array}{l}\text { Number of organs in } \\
\text { progression }\end{array}$} & $1 /$ More & $40.2 \pm 2.8 / 10.8 \pm 0.9$ & $<0.001$ & $40.4 \pm 8.9 / 23.6 \pm 2.9$ & 0.011 \\
\hline \multicolumn{2}{|c|}{ Progression } & $\begin{array}{c}\leq 12 \mathrm{~m} />12 \\
\mathrm{~m}\end{array}$ & NA & NA & $\begin{array}{c}17.97 \pm 7.59 / \\
40.43 \pm 8.9\end{array}$ & $<0.001$ \\
\hline
\end{tabular}

Table 3: Clinical factors influencing the outcome of docetaxel ChT in addition to ADT; bold p-values are significant $(\mathrm{p}<0.05)$. ADT: androgen deprivation therapy; ChT: chemotherapy; CI: confidence interval; HR: hazard ratio; MSKCC: Memorial Sloan Kettering Cancer Center; mOS: median overall survival; mRFS: median relapse-free survival; NA: not applicable; OS: overall survival; PSA: prostate specific antigen; RFS: relapse-free survival; SE: standard error.

ERG status and outcomes. Prostate biopsy tissue samples of 50 patients were examined. Histological samples from the remaining 5 patients were used for primary diagnostic analysis and the remaining samples were too small for further IHC analysis to be performed.

RFS was 16.8 \pm 3.6 months; ERG expression was detected in 21 patients (42\%). ERG positivity was significantly associated with better RFS compared to ERG negativity (median RFS: 26.0 vs. 11.4 months, $\mathrm{p}=0.030$ ) [Figure 4]. 


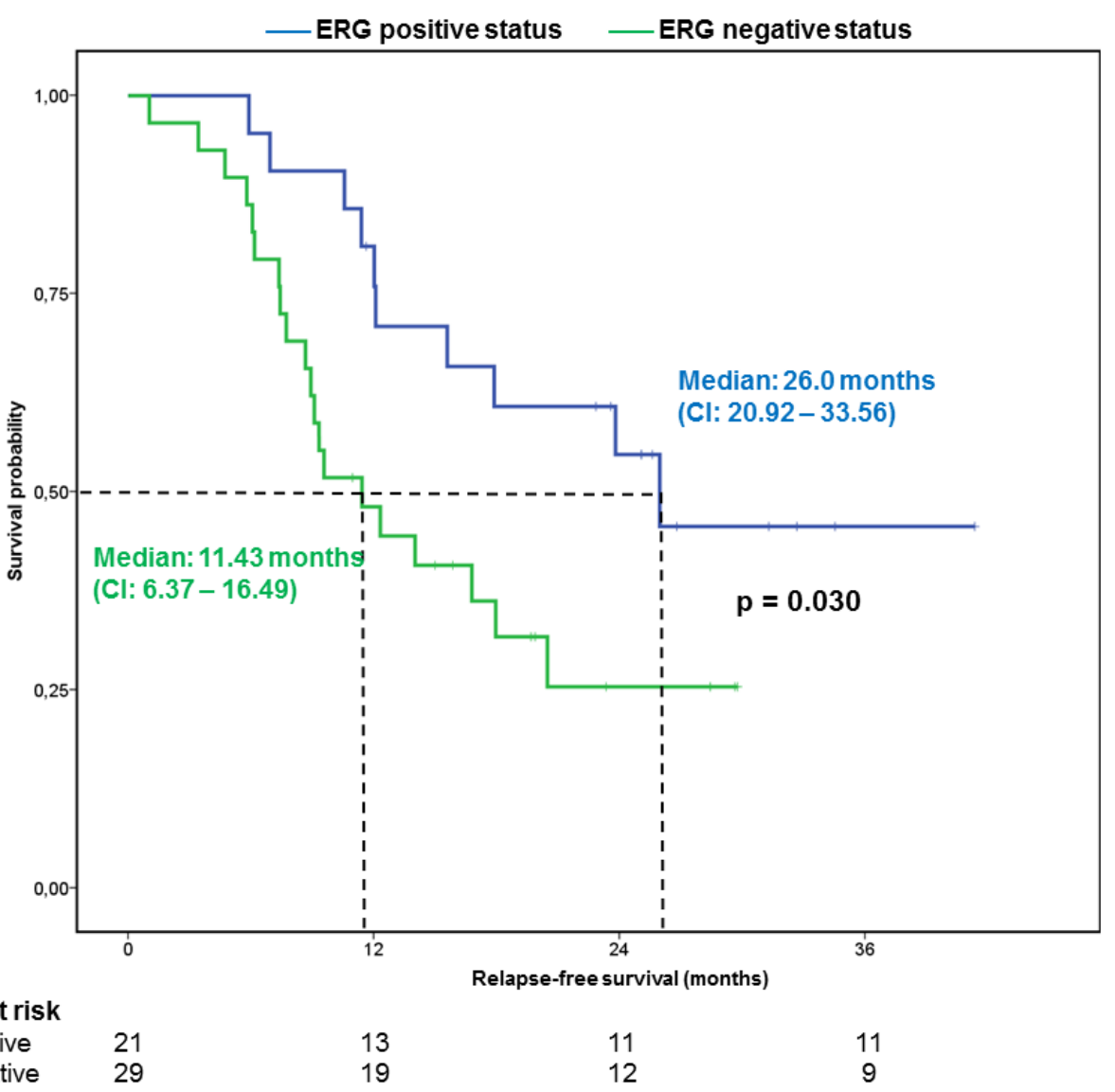

Figure 4: RFS as a function of ERG status. CI: confidence interval; RSF: relapse-free survival.

ERG positivity was also significantly associated with a lower frequency of early progression: progression within 12 months was detected in 5 ERG positive patients vs. in 16 ERG negative patients $(23.8 \%$ vs. $55.2 \%$, p=0.026). Late progression was detected in 16 cases in the ERG positive, and in 13 cases in the ERG negative groups (76.2\% vs. $44.8 \%)$. There was no statistically significant association between ERG status and OS ( $\mathrm{p}=0.107)$.

Toxicity. Adverse events were detected in 28 patients (50.9\%), mostly after the first cycle of docetaxel ChT (23 cases, 41.8\%). The most common adverse events were alopecia, anemia and diarrhea. Most adverse events were grade $0-1$ and could be managed conservatively. None of the observed adverse events led to the discontinuation of docetaxel ChT [Table 4]. 


\begin{tabular}{|l|l|l|l|}
\hline & Grade & $\mathbf{n}$ & \% \\
\hline \multirow{5}{*}{ All } & 0 & 28 & 50.9 \\
\cline { 2 - 4 } & 1 & 23 & 41.8 \\
\cline { 2 - 4 } & 2 & 2 & 3.6 \\
\cline { 2 - 4 } & 3 & 2 & 3.6 \\
\hline Anemia & 0 & 48 & 87.3 \\
\cline { 2 - 4 } & 1 & 5 & 9.1 \\
\cline { 2 - 4 } & 2 & 2 & 3.6 \\
\hline Diarrhea & 0 & 46 & 83.6 \\
\cline { 2 - 4 } & 1 & 9 & 16.4 \\
\hline \multirow{5}{*}{ Leukopenia } & 0 & 36 & 65.5 \\
\cline { 2 - 4 } & 1 & 5 & 9.1 \\
\cline { 2 - 4 } & 2 & 0 & 0 \\
\cline { 2 - 4 } & 3 & 5 & 9.1 \\
\cline { 2 - 4 } & 4 & 9 & 16.4 \\
\hline
\end{tabular}

Table 4: Side effects of docetaxel ChT.

4.2. A Retrospective Analysis of the First $41 \mathrm{mCRPC}$ Patients with Bone Pain Treated with Radium-223 at the National Institute of Oncology in Hungary.

\subsection{1.}

Patient characteristics. Between $23^{\text {rd }}$ July 2014 and $23^{\text {rd }}$ February 2016, 41 patients received Radium-223 treatment at our institute. The mean age of the patients was 72.2 years (SD: 7.1, range: $63-85$ years). At the beginning of therapy, 23 patients had an ECOG status of 0 , and 18 of them had an ECOG status of 1. Ten patients had less than 6 bone metastases, of which only one patient was diagnosed with lymph node metastasis. Of the 31 patients who had at least 6 bone metastases, lymph node metastases were detected in 4 patients [Figure 5]. The mean time from the diagnosis of castration resistant prostate cancer to the beginning of Radium-223 treatment was 20.9 months (SD: 16.3). 


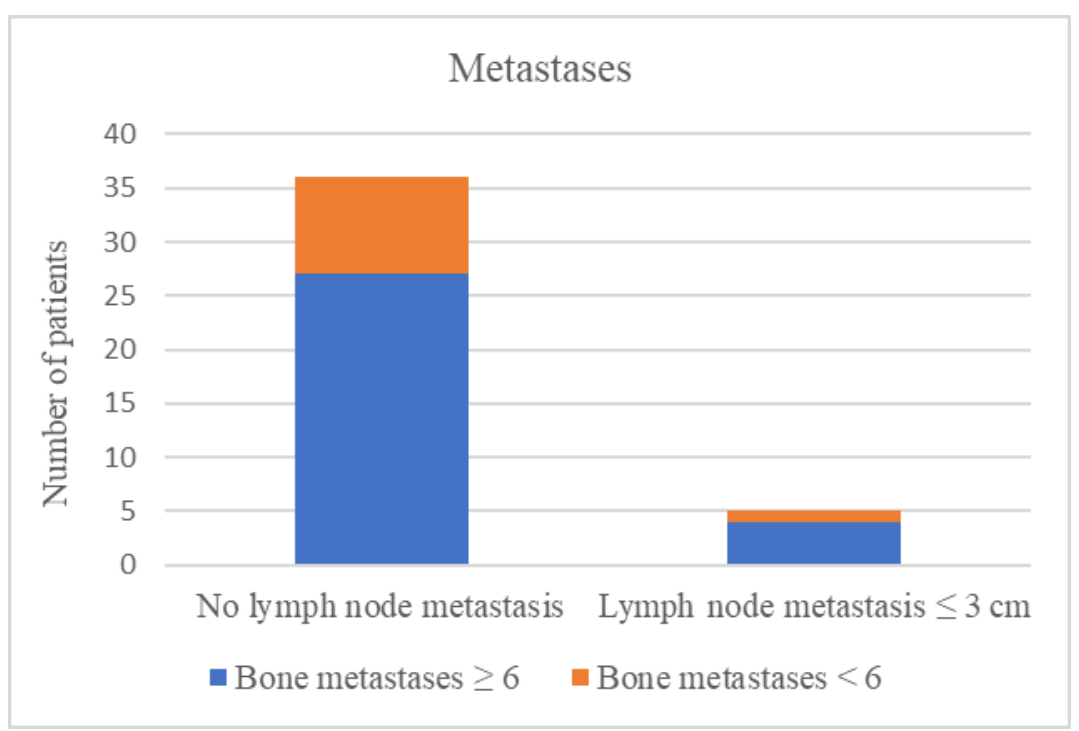

Figure 5 Distribution of patients based on the presence and number of bone and lymph node metastases

\section{Prior treatments and number of cycles}

24 patients received Radium-223 as first-line treatment (58.5\%), 7 patients as second-line treatment (17.1\%), 3 as third-line therapy (7.3\%), 6 as fourth-line treatment (14.6\%), and one patient as fifth-line therapy (2.4\%). Prior treatments included docetaxel (16 patients), abiraterone (10 patients), mitoxantrone (5 patients), cabazitaxel (3 patients), and enzalutamide (1patient) [Table 5].

\begin{tabular}{|c|c|c|}
\hline $\begin{array}{c}\text { Positioning of Radium- } \\
\mathbf{2 2 3}\end{array}$ & $\begin{array}{c}\text { Number of } \\
\text { patients }\end{array}$ & Previous agents \\
\hline First-line & 24 & - \\
\hline Second-line & 7 & $\begin{array}{c}\text { abiraterone } \\
6 \text { docetaxel }\end{array}$ \\
\hline Third-line & 3 & $\begin{array}{c}\text { 1 docetaxel, enzalutamide } \\
2 \text { docetaxel, abiraterone }\end{array}$ \\
\hline Fourth-line & 6 & $\begin{array}{c}\text { 2 docetaxel, abiraterone, cabazitaxel } \\
4 \text { docetaxel, abiraterone, mitoxantrone }\end{array}$ \\
\hline Fifth-line & 1 & $\begin{array}{c}1 \text { docetaxel, abiraterone, mitoxantrone, } \\
\text { cabazitaxel }\end{array}$ \\
\hline
\end{tabular}

Table 5 Distribution of patients based on the positioning of Radium-223 in the treatment sequence, and previous agents 
The median number of cycles administered was 5.5 (SD: 1.1). Altogether 32 patients received the preplanned 6 cycles without delay. 9 patients received a reduced number of cycles due to sudden cardiac death (1 patient), stroke (1 patient), brain metastasis (3 patients), and progression ( 4 patients, 2 of which due to bone marrow failure). Figure 6 shows the brain MRI of a patient with a large brain metastasis invading the frontal lobe who received Radium223 as fifth-line therapy after docetaxel, abiraterone, mitoxantrone, and cabazitaxel treatment. Radium-223 resulted in the complete cessation of bone pain, as a result of which the patient no longer required potent opioid analgesic treatment.
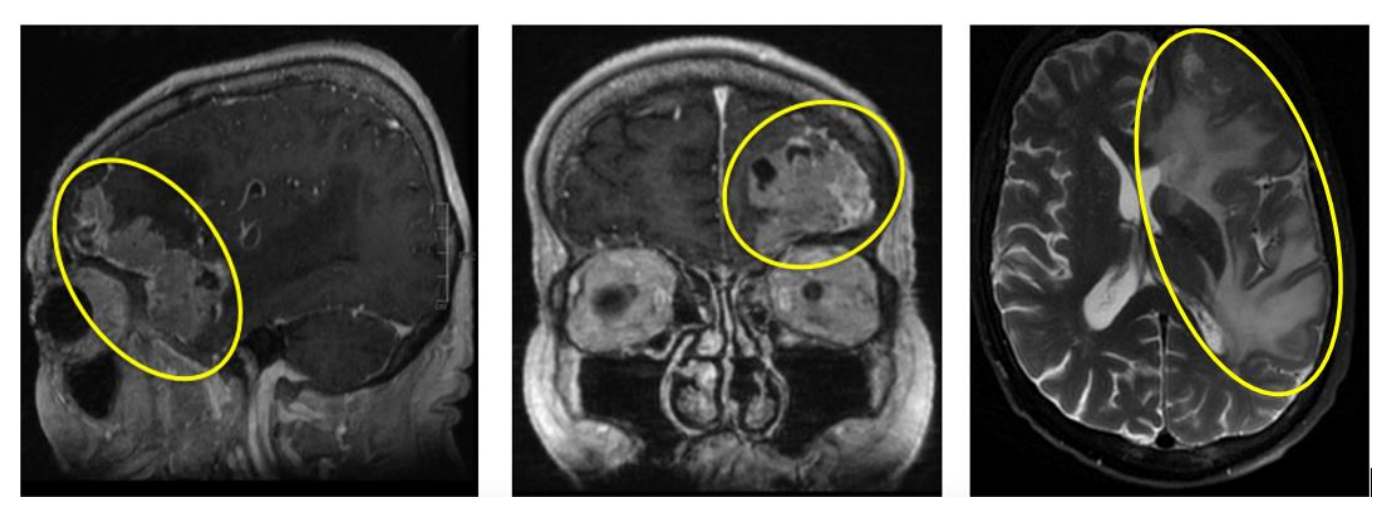

Figure 6 Frontal lobe brain metastasis detected in a mCRPC patient showing behavioral changes

PSA and ALP levels. The mean PSA level at the beginning of treatment was $307.2 \mathrm{ng} / \mathrm{ml}$ (SD: 525.7), which increased to a mean value of $728.5 \mathrm{ng} / \mathrm{ml}$ (SD: 1277) by the end of treatment. The mean ALP level before treatment initiation was 521.1 U/L (SD: 728), while at the end of treatment the last measured mean ALP value was 245.1 U/L (SD: 283.5). 13 patients had elevated baseline ALP levels, of which a 30\% decrease in ALP levels was detected in 3 patients, a 50\% decrease in 6 patients, and altogether 9 patients showed a complete normalization of ALP levels.

Side effects The most common side effects of Radium-223 treatment were also examined. Adverse events were graded according to the Common Terminology Criteria for Adverse Events, version 3.0 (grade 1-4) ${ }^{21}$. The most common adverse event was anemia observed in 11 cases $(26.8 \%), 3$ of which were classified as grade 1,2 as grade 2, and 6 as grade 3. 
Nausea occurred in 9 patients $(21.9 \%)$, all cases were rated as grade 1. Four patients reported treatment-emergent diarrhea (9.8\%), 3 of which were classified as grade 1, and one as grade 2 in severity. Thrombocytopenia developed in 2 patients $(4.9 \%)$, the severity was grade 2 in both cases [Figure 7].

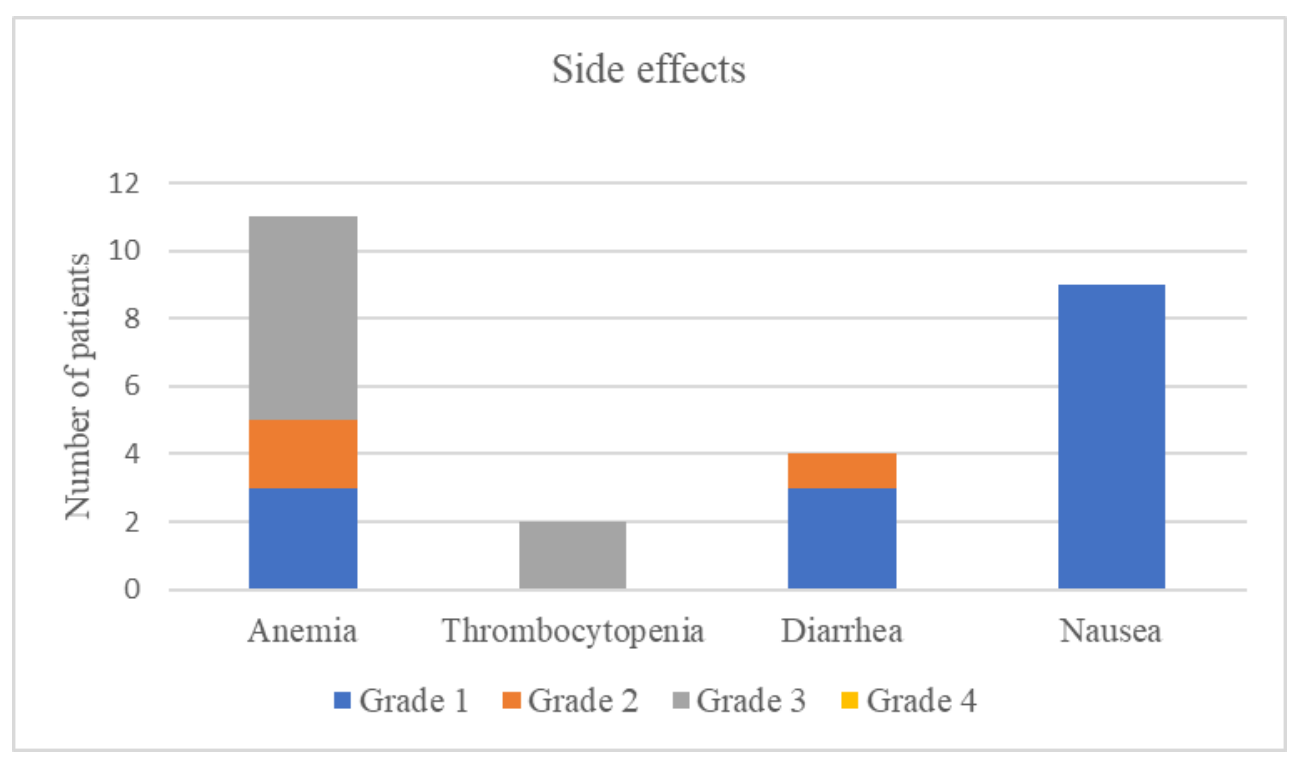

Figure 7 Number and severity of treatment-emergent adverse events

Pain-related outcomes. Before the initiation of Radium-223 therapy, 40 patients were receiving non-steroidal anti-inflammatory drugs (NSAIDs) for pain relief. Nearly two thirds of patients were only receiving one type of analgesics (63.4\%), most of which were NSAIDS (97.6\%). In addition to NSAID treatment, 3 patients were managed with palliative radiotherapy, 5 patients were receiving NSAID + weak opioid, 2 patients were treated with NSAID + weak opioid + radiotherapy, 4 patients were treated with NSAID + major analgesics, one patient with NSAID + major analgesics + radiotherapy, and one patient was only receiving a weak opioid analgesic [Table 6]. 


\begin{tabular}{|c|c|}
\hline Pain management strategy & $\begin{array}{c}\text { Number of } \\
\text { patients }\end{array}$ \\
\hline NSAID & 40 \\
\hline - NSAID + palliative radiotherapy & 3 \\
\hline - NSAID + weak opioid & 5 \\
\hline $\begin{array}{l}\text { - NSAID + weak opioid + } \\
\text { radiotherapy }\end{array}$ & 2 \\
\hline - NSAID + major analgesics & 4 \\
\hline $\begin{array}{l}\text { - NSAID + major analgesics + } \\
\text { radiotherapy }\end{array}$ & 1 \\
\hline Weak opioid & 1 \\
\hline
\end{tabular}

Table 6 Number of patients according to the analgesic treatments received before Radium223 therapy initiation

Two patients reported an increase in pain intensity (4.8\%), 6 patients reported no change (14.6\%), 15 patients experienced decreased pain intensity (36.6\%), and 18 patients reported a complete cessation of pain by the end of Radium-223 therapy (44\%) [Figure 8].

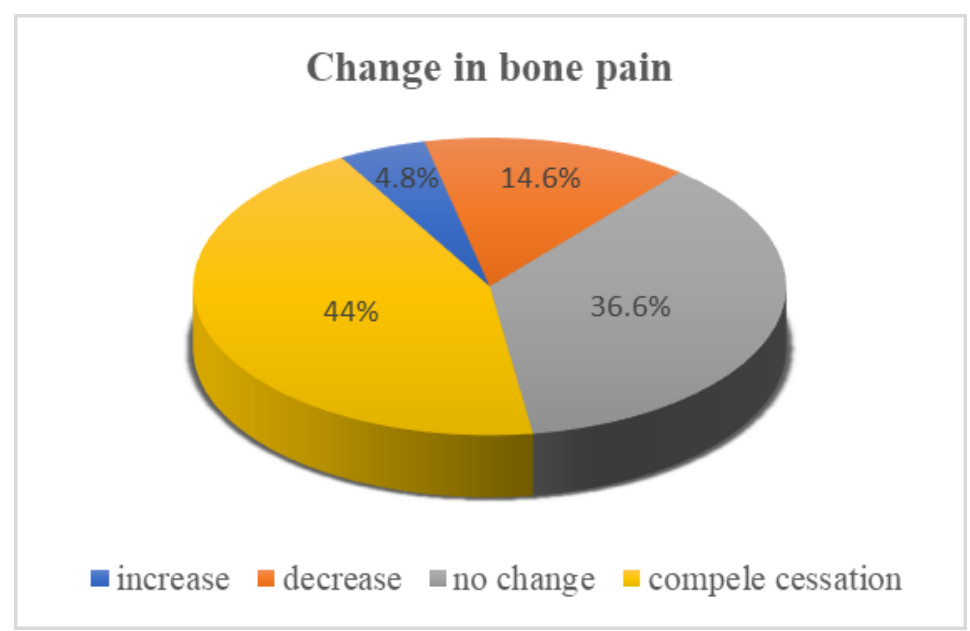

Figure 8 Distribution of patients based on the change in bone pain intensity 
4.3. Abiraterone+prednisolone treatment beyond prostate specific antigen (PSA) and radiographic progression in metastatic castration-resistant prostate cancer patients ( $m C R P C)$ : a retrospective observational one-centre study

4.3.1. Patient characteristics. Clinicopathological parameters of patients in the $\mathrm{N}$ and $\mathrm{T}$ groups are presented in [Table 7]. None of the parameters, but the length of $A A+P$ treatment showed statistical significant difference. In multivariate analysis (logistic regression) none of the parameters was statistically significant for the cohort type ( $\mathrm{N}$ or $\mathrm{T})$. After a median follow-up of 39.7 (95\% CI 37.4-59.8) months the median OS was significantly longer $\left(\mathrm{p}=8 \times 10^{-7}\right)$ in the $\mathrm{T}$ group compared to the $\mathrm{N}$ group: 21.9 (95\% CI 16.9-25) vs. 12.5 (9.3-14.1) months, respectively [Figure 9]. The difference in case of PRP-free survival curves did not reach the level of significance [Figure 10]. Median PSA progression-free survivals (PFS) were $4.1(2.8-7.6)$ and $4.6(2.7-5.7)$ months $(\mathrm{p}=0.90)$ in group $\mathrm{N}$ and $\mathrm{T}$, respectively. The median radiographic PFS were 5.1 (3-7) and 5.7 (4.9-7.8) months $(\mathrm{p}=0.29)$ in group $\mathrm{N}$ and $\mathrm{T}$, respectively. The OS in univariate analysis was significantly influenced by the presence of systemic therapy besides of docetaxel, count of white blood cells, neutrophils and lymphocytes, neutrophil to lymphocyte ratio, starting level of AP and LDH, systemic therapy after $\mathrm{AA}+\mathrm{P}$ and cohort type ( $\mathrm{N}$ or $\mathrm{T}$ ) (data not shown). These (significant) variables were included in the multivariate Cox regression analysis of OS. Besides of cohort type the AP level at the start of therapy and systemic therapy after AA+P proved to be independent predictors of OS [Table 8]. The PSA PFS in univariate analysis was significantly influenced by 11 parameters, but out of them only 3 was significant in COX multivariate regression: $\geq 25 \%$ increase in PSA level after 3 month compared to the start or to the first month and LDH level after 1 month compared to the first month (data not shown). The radiographic PFS in univariate survival analysis was significantly influenced by 14 variables and out of them only the $\geq 25 \%$ increase in AP level after 3 month and that of PSA level after 1 months compared to the start proved to be independent factors in Cox multivariate analysis (data not shown). The treatment was well tolerated. In contrast to other studies [41,42] no drug related adverse events of grade 3-4 were detected among our patient. 
Table 7 Clinicopathologic characteristics of patients with castration-resistant prostate cancer treated with abiraterone acetate + prednisolone $(\mathrm{AA}+\mathrm{P})$

\section{Parameters}

$\mathrm{N}$

Age [years] median (range)

Metastasis at diagnosis

Multiple metastases at the start of $\mathrm{AA}+\mathrm{P}$

Metastasis

Bone
Lymph node
Visceral
Liver
Lung

Gleason score median (range)

$\geq 7$

$<7$

n.a.

Surgery

Irradiation

Only docetaxel

Docetaxel+other systemic therapy

Systemic therapy after AA+P

Taxoid (docetaxel, cabazitaxel)

Mitoxantron

Other $\left({ }^{223} \mathrm{Ra}\right.$, custirsen $)$

Hemoglobin $[\mathrm{g} / \mathrm{dl}]$ median (range)

$$
\begin{aligned}
& \geq 14^{*} \\
& <14
\end{aligned}
$$

n.a.

Neutrophil count [G/l] median (range)

$>7 * *$

$\leq 7$

n.a.

Lymphocyte count [G/l] median (range)
All patients

N

113

70 (49-90)

54

81

103

44

64

14

15

7.8 (3-10)

81

18

14

18

72

41

59

$27(12,15)$

27

$5(3,2)$

11.8 (8.4-15.1)

\section{2}

107

4

$5.0(1-16.9)$

22

80

11

$1.5(0.5-3.4)$ $\geq 1 * *$

$<1$

n.a

\section{Group N}

N (\%)

57

70 (49-88)

25 (44)

39 (68)

49 (86)

20 (35)

33 (58)

8 (14)

9 (16)

8 (4-10)

42 (84)

8

6

$12(21)$

0

34 (60)

23 (40)

28 (49)

$12(6,6)$

14

$2(1,1)$

11.7 (8.8-13.7)

0

56

1

4.9 (1-10.8)

14 (27)

37

6

1.4 (0.6-3.4)

$36(75)$

12

9
Group T

N (\%)

56

70.6 (49-90)

29 (52)

42 (75)

54 (96)

24 (43)

31 (55)

$6(11)$

$6(11)$

7.7 (3-10)

39 (80)

10

8

6 (11)

15 (26) 15 (27)

38 (68)

18 (32)

$31(55)$

$15(9,6)$

13

$3(2,1)$

12 (8.4-15.1)

2 (4)

51

3

5.3 (2.4-16.9)

8 (16)

43

5

$1.6(0.5-3.3)$

35 (78)

10

11 


\begin{tabular}{|c|c|c|c|}
\hline NLR median (range) & $3.6(0.5-12.6)$ & $3.7(0.5-12.3)$ & $3.0(1.3-12.6)$ \\
\hline$\geq 3.6$ & 45 & $25(52)$ & $20(44)$ \\
\hline$<3.6$ & 48 & 23 & 25 \\
\hline n.a. & 20 & 9 & 11 \\
\hline \multicolumn{4}{|l|}{ Alkaline phosphatase [U/l] median (range) } \\
\hline At the start of therapy & $347(138-7181)$ & $399(146-7181)$ & $304(138-4562)$ \\
\hline$>290^{*}$ & 66 & $37(66)$ & $29(56)$ \\
\hline$\leq 290$ & 42 & 19 & 23 \\
\hline n.a. & 5 & 1 & 4 \\
\hline After 1 month & $473(113-4534)$ & $579(150-4534)$ & $450(113-4157)$ \\
\hline$\geq 290$ & 78 & $41(75)$ & $37(66)$ \\
\hline$<290$ & 33 & 14 & 19 \\
\hline n.a. & 2 & 2 & 0 \\
\hline$\geq 25 \%$ decrease vs. start & $3 / 106$ & $2 / 54(4)$ & $1 / 52(2)$ \\
\hline$\geq 25 \%$ increase vs. start & $55 / 106$ & $27 / 54(50)$ & $28 / 52(54)$ \\
\hline After 3 months & $427(99-4352)$ & $427(153-4352)$ & $455(99-2827)$ \\
\hline$\geq 290$ & 63 & $29(63)$ & $34(64)$ \\
\hline$<290$ & 36 & 17 & 19 \\
\hline n.a. & 14 & 11 & 3 \\
\hline$\geq 25 \%$ decrease vs. start & $14 / 95(15)$ & $8 / 45(18)$ & $6 / 50(12)$ \\
\hline$\geq 25 \%$ increase vs. start & $38 / 95(40)$ & $16 / 45(36)$ & $22 / 50(44)$ \\
\hline$\geq 25 \%$ decrease vs. 1 month & $28 / 98(29)$ & $14 / 45(31)$ & $14 / 53(26)$ \\
\hline$\geq 25 \%$ increase vs. 1 month & $20 / 98(20)$ & $12 / 45(27)$ & $8 / 53(15)$ \\
\hline
\end{tabular}

Lactate dehydrogenase [U/1] median (range)

$\begin{array}{lccc}\text { At the start of therapy } & 482(236-2487) & 526(247-2363) & 459(236-2487) \\ >451^{*} & 67 & 37(66) & 30(59) \\ \leq 451 & 40 & 19 & 21 \\ \text { n.a. } & 6 & 1 & 5 \\ \text { After } 1 \text { month } & 470(226-1960) & 509(290-1960) & 445(226-1068) \\ >451 & 65 & 37(67) & 27(49) \\ \leq 451 & 46 & 18 & 28 \\ \text { n.a. } & 2 & 2 & 1 \\ \text { After } 3 \text { months } & 469(262-3603) & 493(283-3603) & 458(262-976) \\ >451 & 59 & 30(65) & 29(56) \\ \leq 451 & 39 & 16 & 23 \\ \text { n.a. } & 15 & 11 & 4\end{array}$


PSA [ng/ml] median (range)

$\begin{array}{lccc}\text { At the start of therapy } & 161(1.2-1990) & 191(7.7-1990) & 131(1.2-1335) \\ >161 & 53 & 29(57) & 24(44) \\ \leq 161 & 53 & 22 & 31 \\ \text { n.a. } & 7 & 6 & 1 \\ \text { After } 1 \text { month } & 104(0.8-5804) & 114(2.6-5804) & 101(0.8-1735) \\ >161 & 35 & 19(46) & 16(36) \\ \leq 161 & 51 & 22 & 29 \\ \text { n.a. } & 27 & 16 & 11 \\ \geq 25 \% \text { decrease vs. start } & 35 / 81(43) & 20 / 37(54) & 15 / 44(34) \\ \geq 25 \% \text { increase vs. start } & 27 / 81(33) & 9 / 37(24) & 18 / 44(41) \\ \text { After } 3 \text { months } & 111(0.8-6303) & 126(1.4-6303) & 105(0.8-1467) \\ >161 & 38 & 17(38) & 21(40) \\ \leq 161 & 60 & 28 & 32 \\ \text { n.a. } & 15 & 12 & 3 \\ \geq 25 \% \text { decrease vs. start } & 38 / 89(43) & 16 / 37(43) & 22 / 52(42) \\ \geq 25 \% \text { increase vs. start } & 36 / 89(40) & 15 / 37(41) & 21 / 52(40) \\ \geq 25 \% \text { decrease vs. } 1 \text { month } & 23 / 74(31) & 9 / 31(29) & 14 / 43(33) \\ \geq 25 \% \text { increase vs. } 1 \text { month } & 30 / 74(41) & 14 / 31(45) & 16 / 43(37)\end{array}$

From diagnose to HT [months] mean (range) 0.5 (0-8.8)

$\begin{array}{ll}>0.5 & 13 \\ \leq 0.5 & 100\end{array}$

$0.7(0-8.8) \quad 0.4(0-8.4)$

$8(14) \quad 5(9)$

$49 \quad 51$

HT duration [months] median (range) 19.1 (1-130)

$\begin{array}{lr}>19.1 & 54 \\ \leq 19.1 & 59\end{array}$

From HT to AA+P [months] median (range) 2.4 (0.7-10.7)
$>2.4$
51
$\leq 2.4$
62

From CT to AA+P [months] median (range) 0.5 (0-3.8)

$\begin{array}{lr}>0.5 & 54 \\ \leq 0.5 & 58\end{array}$

AA+P duration [months] median (range) 6.4 (1-32.2)

$\begin{array}{lr}>6.4 & 57 \\ \leq 6.4 & 56\end{array}$

CT - chemotherapy; Group N - patients at AA+P treatment until PSA and radiographic progression (PRP); Group T - patients at AA+P treatment beyond PRP until clinical progression; HT - hormone therapy; NLR - neutrophil to lymphocyte ratio; PSA - prostate specific antigen

* lower normal limit, $* *$ upper normal limit, ${ }^{*} \mathrm{p}<0.01$ 
Table 8 Independent predictors of overall survival in patients with castration-resistant prostate cancer treated with AA+P

\section{Parameter}

\section{HR $\quad 95 \%$ CI $P$}

Alkaline phosphatase (U/l) at the start of therapy

$\begin{array}{llll}\geq 290 & 1 & \text { reference } & \\ <290 & 0.6 & 0.3-0.9 & 0.020\end{array}$

Systemic therapy after AA+P

$\begin{array}{llll}\text { Yes } & 1 & & \\ \text { No } & 1.7 & 1.1-2.8 & 0.029\end{array}$

Study cohort

$\begin{array}{llll}\text { Group N } & 1 & \text { reference } & \\ \text { Group T } & 0.3 & 0.2-0.5 & <0.001\end{array}$

HR - hazard ratio of multivariate Cox regression analysis; CI - confidence interval; other abbreviations as in Table 8.

Figure 9. Overall survival (OS) of metastatic castration-resistant prostate cancer patients treated with abiraterone acetate + prednisolone until PSA and radiographic progression (PRP) (group N, solid line) or beyond PRP until clinical progression (group T, dashed line).

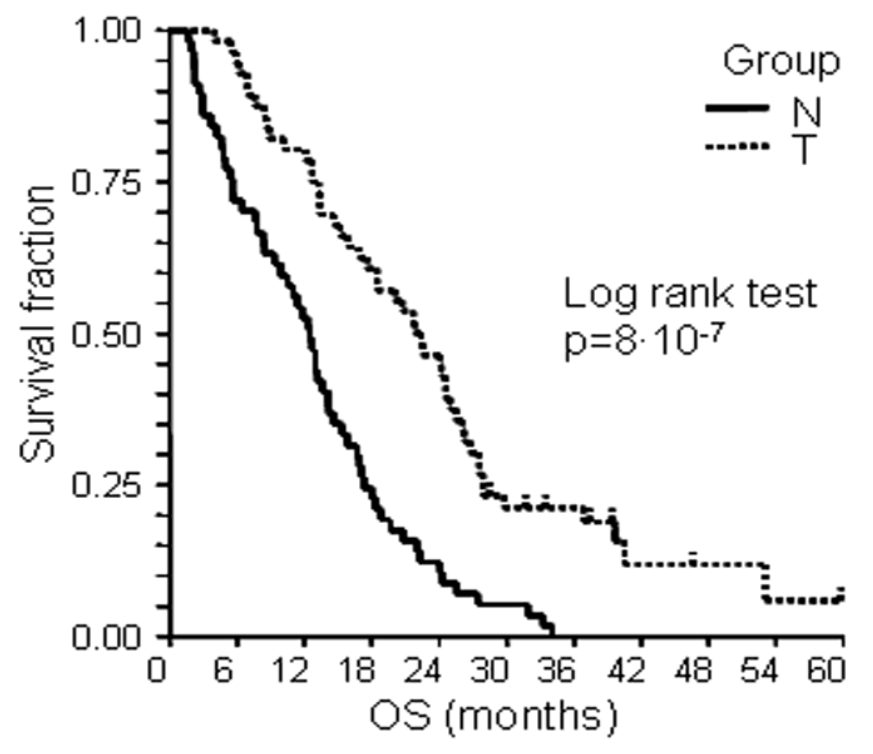


Figure 10. Progression-free survival (PFS) according to PSA and radiographic progression of metastatic castration-resistant prostate cancer patients treated with abiraterone acetate + prednisolone until PSA and radiographic progression (PRP) (group N, solid line) or beyond PRP until clinical progression (group $\mathrm{T}$, dashed line).
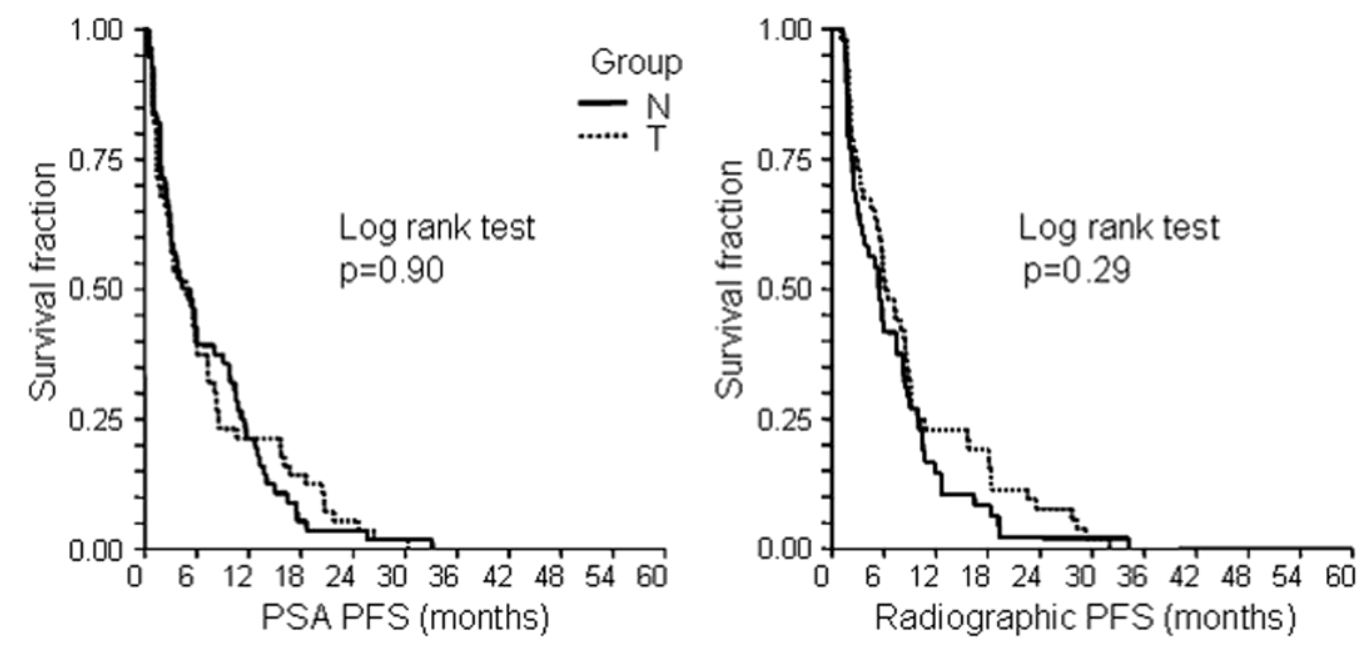

\section{Discussion}

\subsection{ERG Expression Can Predict the Outcome of Docetaxel Combined with Androgen} Deprivation Therapy in Metastatic Hormone-Sensitive Prostate Cancer

In our cohort of mHSPC patients treated with early docetaxel and ADT, we examined the potential relationship between clinical factors as well as ERG expression and response to docetaxel therapy. ERG positivity and good PSA response were strongly associated with better relapse-free survival, and ERG expression was also associated with a lower frequency of early progression. The combined docetaxel + ADT regimen was well-tolerated; no new adverse events were recorded during a mean cycle number of 5.69. 
Recently, there was a paradigm shift in the management of mHSPC. Until 2014, the only available therapy for these patients was ADT, and most of the research focused on patients with castration-resistant disease. The introduction of early docetaxel or abiraterone in addition to ADT in the hormone-sensitive phase opened new perspectives in the management of mHSPC by providing similar benefits in terms of OS compared to ADT alone. However, there are certain aspects that need to be taken into consideration when choosing between docetaxel and abiraterone in eligible patients, such as the expected duration of therapy, and treatment costs. Although early docetaxel chemotherapy may be associated with well-known side-effects, it is cost-effective compared to abiraterone, and the fix number of 6 cycles allow for the planning of therapy. However, biomarkers predicting response to docetaxel are needed to identify patients who would benefit from early docetaxel.

The role of the TMPRSS2: ERG fusion gene as a potential biomarker of response to docetaxel chemotherapy among patients with mHSPC receiving ADT has been suggested by several authors [15, 43, 44]. Rajpar et al. analyzed data from the phase III GETUG-12 and GETUG15 studies, which assessed the role of docetaxel chemotherapy in combination with ADT in the setting of high-risk localized or metastatic HSPC, respectively. In both datasets, docetaxel-based chemotherapy was associated with improved RFS in ERG positive patients, but not in ERG negative patients, suggesting a potential role for ERG as an important biomarker of the effectiveness of docetaxel chemotherapy [45]. In the present study, ERG positivity was also significantly associated with better RFS and a lower frequency of early progression, than ERG negative status among mHSPC patients treated with early docetaxel and ADT. Furthermore, the finding that good PSA response was associated with better RFS is in line with previous observations suggesting a predictive value for PSA progression in terms of survival in metastatic prostate cancer [46] and complements the existing knowledge base with new data from mHSPC patients receiving the early docetaxel + ADT regimen. Limitations of our study include the small sample size and the retrospective nature of our research.

\subsection{A Retrospective Analysis of the First 41 mCRPC Patients with Bone Pain Treated with} Radium-223 at the National Institute of Oncology in Hungary.

This was a single-center retrospective study of patients with mCRPC receiving Radium-223 for the treatment of bone metastases at the National Institute of Oncology, Hungary. To the best of our knowledge, this is the first study in Hungary to analyze the experience with 
Radium-223 in a real-world setting since its introduction into clinical practice in 2014. In our cohort of patients with symptomatic mCRPC, Radium-223 proved to be effective in terms of pain relief, with moderate side effects. No PSA response was detected, while total ALP levels significantly decreased by the end of treatment. Our findings should be interpreted in view of the clinical evidence supporting the use of Radium-223 for the treatment of bone metastases in $\mathrm{mCRPC}$ patients.

The phase III, double-blind, randomized Alpharadin in Symptomatic Prostate Cancer Patients (ALSYMPCA) trial investigated the efficacy and safety of Radium-223 compared to placebo, in addition to the best standard of care, in men with castration-resistant prostate cancer and bone metastases [33]. Radium-223 significantly prolonged overall survival, the time to first symptomatic skeletal event, and reduced the risks of external beam radiation therapy for bone pain, and spinal cord compression [21]. The most common adverse reactions associated with Radium-223 treatment in the ALSYMPCA trial were nausea, diarrhea, vomiting, and peripheral edema. The most common hematologic laboratory abnormalities in the Radium223 arm were anemia, lymphocytopenia, leukopenia, thrombocytopenia, and neutropenia [22].

Our clinical experience is in line with the results of the ALSYMPCA trial in terms of the efficacy and safety of Radium-223 treatment. The most common side effects observed in our patient cohort were anemia and nausea, other adverse events included thrombocytopenia and diarrhea. The reported adverse events were not severe, and none of them required the treatment discontinuation. The majority of patients receiving Radium-223 at our institute experienced a significant reduction of bone pain by the end of treatment.

Radium-223, as compared with placebo, significantly prolonged the time to an increase in the total ALP levels, and the time to an increase in PSA levels in the ALSYMPCA trial [33]. In our cohort, Radium-223 treatment resulted in a significant reduction of baseline total ALP levels. The majority of patients (70\%) having elevated ALP levels at baseline achieved a complete normalization by the end of treatment, and a decrease of at least $50 \%$ was observed in $46 \%$ of these patients. On the other hand, we found an increase in mean PSA levels by the end of treatment. However, it has to be noted that nearly half of our patients were not receiving Radium-223 as first-line therapy. In a recent retrospective study [47], Radium-223 treatment in mCRPC was associated with an increase in PSA in the majority of heavily pretreated patients, the significance of which is still uncertain. Despite the fact that we did not observe a PSA response, 3 of our patients showed a gradual increase in PSA levels after treatment initiation, which started to decrease after 2 months. This phenomenon is in line with 
a previous case report revealing a temporary pain and PSA 'flare' after the first dose of Radium-223[48], which may indicate massive tumor cell lysis, and may be associated with a more complete and more persistent response to Radium-223. Nevertheless, it has to be noted that Radium-223 is not supposed to treat prostate cancer itself or slow down disease progression. The primary purpose is to treat bone metastases and reduce bone pain, thus improving quality of life and prolonging survival. Therefore, changes in ALP levels should be preferred over PSA when it comes to monitoring the efficacy of Radium-223 therapy in terms of bone metastases and the reduction of bone pain.

One of the important remaining questions is the appropriate sequencing of agents for mCRPC in the larger context of response/survival benefit and risk/safety profile of various approved agents in the CRPC spectrum. In a prespecified subgroup analysis of the ALSYMPCA trial [49], Radium-223 was effective and well-tolerated, irrespective of previous docetaxel use. In our cohort, more than half of the patients received Radium-223 as first-line therapy, but the most common previous agent used was docetaxel. The fact that in the majority of patients bone pain intensity significantly improved by the end of treatment supports the positioning of Radium-223 as a first-line option for a large number of patients with symptomatic mCRPC and bone metastases. Another frequently discussed concern is optimal patient selection, i.e. the identification of patients who would benefit the most from Radium-223 therapy. Patients with mCRPC and bone metastases are often fragile with a poor general condition, therefore the development of treatment-emergent side effects, particularly bone marrow failure, might often require therapy discontinuation. In our cohort, the incidence of bone marrow failure was low, and none of the reported adverse events required the cessation of treatment, although a significant proportion of patients were heavily pretreated before the initiation of Radium-223 therapy.

Our observations regarding the baseline characteristics of patients with mCRPC and bone metastases highlights significant unmet needs in the field of pain management. Despite the commonly known World Health Organization cancer pain treatment step ladder and the generally poor health status of patients receiving Radium-223 as second-, third-, fourth-, or fifth-line therapy, a significant proportion of our patients were only receiving one type of analgesics at treatment initiation, most of which were NSAIDs. Furthermore, only a small proportion of patients were treated with major analgesics, and in many cases, combination analgesic therapy was not in line with current recommendations. These findings are in accordance with previous observations. A recent study examining the prevalence and severity of pain in unselected outpatients with mCRPC found that pain is commonly present, 
commonly undertreated, and often severe in these patients. Moreover, the study revealed an apparent underuse of analgesics, including narcotic analgesics, among patients with pain [50]. Suboptimal pain management in the MCRPC patient population might be due to the lack of clinical trials assessing pain palliation in a manner that could support a label for this purpose, and the resulting uncertainties of treating physicians. Our observations suggest that there is still room for improvement regarding pain management in patients with mCRPC, and highlight the importance of a comprehensive approach.

Interestingly, 3 of our patients were diagnosed with brain metastasis during Radium-223 treatment $(7.3 \%)$, the suspicion of which was raised by epileptic seizures in all cases. Brain metastasis in men with mCRPC is not common, and appears to occur in less than 3 percent of all men with hormonally treated prostate cancer based on three large reviews on the incidence of brain metastasis from prostate cancer [51-53].However, emerging evidence suggests that the incidence of brain metastasis may have been rising over recent years may be due to the fact that the range of effective treatment options has been increasing and patients live longer with metastatic disease[54] Therefore, the improved survival associated with the introduction of new agents including Radium-223 is likely to 'unmask' brain metastases that would otherwise remain clinically silent. Our experience supports this hypothesis, and suggests that physicians should suspect the possibility of brain metastasis in MCRPC patients developing central symptoms. Furthermore, in heavily pretreated patients, performing head CT before the initiation of Radium-223 therapy may be recommended, allowing for the early detection and management of asymptomatic brain metastasis.

Our clinical experience suggests that Radium-223 is a safe and effective treatment option for patients with mCRPC and bone metastases. In our study, Radium-223 therapy was associated with a significant reduction in bone pain intensity, which was accompanied by a decrease in total ALP levels. The majority of reported adverse events were mild or moderate. Further research is required to optimize patient selection and determine the positioning of Radium223 in the treatment sequence of patients with symptomatic mCRPC and bone metastases. 
5.3. Abiraterone+prednisolone treatment beyond prostate specific antigen (PSA) and radiographic progression in metastatic castration-resistant prostate cancer patients ( $m C R P C)$ : a retrospective observational one-centre study

In this retrospective study the treatment with $\mathrm{AA}+\mathrm{P}$ beyond PSA and radiographic progression significantly improves survival. To our knowledge this phenomenon connected to $\mathrm{AA}+\mathrm{P}$ treatment is new in the literature. The dissimilarity between the two subgroups was only the definition of progression, otherwise they were homogeneous. In this analysis predictive factors of OS were also investigated, therefore, all variables, which significantly influenced OS in the univariate analysis, were included in the multivariate Cox regression analysis. Besides of cohort type (T or N) the ALP level at the start of therapy and systemic treatment after AA+P proved to be independent predictors of OS. The ALP level were already proved to be independent prognostic factor in an earlier study [55] and another study provided evidence of clinical benefit for subsequent chemotherapy in men with advanced prostate cancer whose disease progressed after treatment with AA [56].

During the chemotherapy era the treatment of patients just until progression was a fundamental postulate. It seems that with novel treatment options the situation is changing. Some evidence suggests that, in certain circumstances, continuing a therapy beyond disease progression can be successful, and several papers address this topic. Treatment of renal cell cancer beyond progression with nivolumab [57], breast cancer with bevacizumab [58] or with trastuzumab [59], colorectal cancer with bevacuzimab [60] or with irinotecan [61] resulted in unexpected beneficial results. In mCRPC androgen deprivation therapy is a life-long treatment irrespectively of disease progression. This is based on the hypothesis that cessation of androgen suppression, with the recovery of androgen production, might allow accelerated tumor growth $[62,63]$.

Progression during $\mathrm{AA}+\mathrm{P}$ treatment or resistance may be explained by the generation of constitutively active androgen receptor (AR) splice variants [64]. It was indicated that DDX39B (also known as UAP56, a member of RNA-helicases) may be associated with malignant progression of prostate cancer through promoting splice variant AR generation [65]. It was also shown, that UAP56 can be down regulated by inhibition of the PI3K pathway [66]. An inhibitor of PI3K, PX-866, a derivative of wortmannin, was investigated in a trial of mCRPC patients receiving AA+prednisone, but the addition of PX-866 to AA+prednisone in unselected patients progressing on AA+prednisone showed no evidence of antitumor effects. The authors conclude that strategies to combine PI3K inhibition with AR targeted therapies 
should consider initiation earlier in the disease course and/or recruiting a selected population [67]. We can agree with their conclusion as the glucocorticoids increases the PTEN expression, which acts as the catalytic antagonist of PI3K [68], thus during the prednisone treatment further decrease in expression of AR splice variants by using PX-866 is unlikely (it would be interesting to use PX-866 along AA in glucocorticoid-naïve mCRPC patients). The above data indicate that only by the presence of AR splice variants the antitumor effect of AA beyond progression can not be explained. It can be rather supposed that besides of AAsensitive cancer cells during AA treatment enhanced proliferation of AA-resistant subclones is favored and subsequently progression is manifested. At this stage withdrawal of AA may lead to uncontrolled proliferation of both clones (AA-resistant and AA-sensitive), while the continuous AA treatment let only the AA-resistant subclone to proliferate.

The growing number of malignancies and drugs that challenge the custom of terminating treatment at progression warrants an in-depth examination of the definitions of disease progression. Measuring the change in tumor burden is crucial in the clinical evaluation of cancer therapeutics. The definition of regression or progression is based on anatomical bidimensional measurement of tumor size and clinical trial endpoints and therapy decisions depend on these results. However endpoints like objective response and time to disease progression are useful only if these criteria are based on widely accepted and readily applied standard criteria. The first tumor response criteria were published by the WHO in 1981[69]. In 2000 RECIST (Response Evaluation Criteria in Solid Tumors) [70], in 2009 RECIST 1.1 was published [71]. All these criteria were not appropriate for prostate cancer patients, since $70-80 \%$ of mCRPC patients do not have bidimensionally measurable disease. To address this problem the first prostate specific eligibility and response guideline for androgen independent prostate cancer was published in 1999 [72], which was followed in 2008 (in the docetaxel era) by the PCWG2 recommendation [35]. The changing therapeutic landscape called for new trial endpoints. Both in the COU-AA-3015[41], and in the AA EAP trials [42], patients were treated until PSA, radiographic and clinical progression. In 2016 PCWG3 introduced the concept of no longer clinically benefiting to emphasize the distinction between first evidence of progression and the clinical need to terminate or change treatment. Our result, which showed that treating mCRPC patients with AA+P beyond PRP significantly improves survival, underscores the importance of this distinction. Based on our result we can hypothesize that longer treatment with $\mathrm{AA}+\mathrm{P}$ - at least until clinical progression - results in better survival. It is important to note that the whole clinical picture - and not just response 
criteria - should be taken into account when deciding which patients to treat beyond first progression.

There are some limitations of this analysis, which should be taken into consideration. The current retrospective analysis comprised a relatively small number of patients treated beyond RECIST-defined first progression. The ideal starting point and length of AA+P treatment can only be defined with prospective randomized trials.

\section{Summary, Conclusions}

6.1.: ERG expression may have a potential predictive value with respect to the effectiveness of docetaxel chemotherapy combined with ADT.

6.2. Radium-223 proved to be efficient in terms of pain relief, with moderate side effects. No PSA response was detected, while alkaline phosphatase levels significantly decreased

6.3. Low levels of AP at the start of treatment, systemic therapy applied after AA+P and treatment beyond PRP proved to be independent factors of longer OS.

\section{Acknowledgements}

First of all I am most grateful to my supervisor, Anikó Maráz, associate professor, who encouraged and supported me in the completion of this work.

I express my gratitude to Lajos Géczi my present Head of Department and Professor István Bodrogi, the previous Head of Department of the National Institute of Oncology.

I am greatly indebted to chief medical officer Krisztina Bíró, who provided me continuous support.

I would like offer my special thanks for their assistance in doing the statistics to Zoltán Varga, Ágnes Kovács and Barna Budai.

I would like to thank Farkas Sükösd, pathologist and his collegaues for helping me in the analysis of ERG expression. 


\section{References:}

1. Huggins C, Hodge C.: Studies on Prostatic Cancer. I. The Effect of Castration, of Estrogen and of Androgen Injection on Serum Phosphatases in Metastatic Carcinoma of the Prostate. Cancer Research. 1941; 1:293-7.

2. Küronya Z, Bíró K, Géczi L, et al. Treatment strategies for advanced prostate cancer. Magy Onkol. 2015 Sep;59(3):229-40. Hungarian.

3. Riesz P, Nyírádi P. Novelties in diagnostics and treatment of prostate cancer. Orv Hetil. 2016 Mar 13;157(11):410-4. Hungarian.

4. Sweeney CJ, Chen YH, Carducci M, et al. Chemohormonal Therapy in Metastatic Hormone-Sensitive Prostate Cancer. N Engl J Med. 2015 Aug 20;373(8):737-46.

5. James ND, Sydes MR, Clarke NW, et al. Addition of docetaxel, zoledronic acid, or both to first-line long-term hormone therapy in prostate cancer (STAMPEDE): survival results from an adaptive, multiarm, multistage, platform randomised controlled trial. Lancet. 2016 Mar 19;387(10024):1163-77.

6. Fizazi K, Tran N, Fein L, et al. Abiraterone plus Prednisone in Metastatic, CastrationSensitive Prostate Cancer. N Engl J Med. 2017 Jul 27;377(4):352-360.

7. James ND, de Bono JS, Spears MR, et al. Abiraterone for Prostate Cancer Not Previously Treated with Hormone Therapy. N Engl J Med. 2017 Jul 27;377(4):338351.

8. McNamara M, Sweeney C, Antonarakis ES, et al. The evolving landscape of metastatic hormone-sensitive prostate cancer: a critical review of the evidence for adding docetaxel or abiraterone to androgen deprivation. Prostate Cancer Prostatic Dis. 2017 Dec 20. doi: 10.1038/s41391-017-0014-9. [Epub ahead of print]

9. Darr C, Krafft U, Hadaschik B, et al. The Role of YKL-40 in Predicting Resistance to Docetaxel Chemotherapy in Prostate Cancer. Urol Int. 2018;101(1):65-73.

10. Rescigno P, Lorente D, Dolling D, et al. Docetaxel Treatment in PTEN- and ERGaberrant Metastatic Prostate Cancers. Eur Urol Oncol. 2018 May;1(1):71-77.

11. Ferraldeschi R, Nava Rodrigues D, Riisnaes R, et al. PTEN protein loss and clinical outcome from castration-resistant prostate cancer treated with abiraterone acetate. Eur Urol. 2015 Apr;67(4):795-802.

12. Tomlins SA, Rhodes DR, Perner S, et al. Recurrent fusion of TMPRSS2 and ETS transcription factor genes in prostate cancer. Science. 2005 Oct 28;310(5748):644-8. 
13. Esgueva R, Perner S, J LaFargue C, et al. Prevalence of TMPRSS2-ERG and SLC45A3-ERG gene fusions in a large prostatectomy cohort. Mod Pathol. 2010 Apr;23(4):539-46.

14. Adamo P, Ladomery MR. The oncogene ERG: a key factor in prostate cancer. Oncogene. 2016 Jan 28;35(4):403-14.

15. Galletti G, Matov A, Beltran H, et al. ERG induces taxane resistance in castrationresistant prostate cancer. Nat Commun. 2014 Nov 25; 5:5548. doi: $10.1038 /$ ncomms6548.

16. Hotte SJ, Saad F. Current management of castrate-resistant prostate cancer. Curr Oncol. 2010 Sep;17 Suppl 2: S72-79.

17. Attard G, Parker C, Eeles RA, Schröder F, Tomlins SA, Tannock I, Drake CG, de Bono JS. Prostate cancer. Lancet. 2016 Jan 2;387(10013):70-82. doi: 10.1016/S01406736(14)61947-4.

18. DePuy V, Anstrom KJ, Castel LD, Schulman KA, Weinfurt KP, Saad F. Effects of skeletal morbidities on longitudinal patient-reported outcomes and survival in patients with metastatic prostate cancer. Support Care Cancer. 2007 Jul;15(7):869-876.

19. Bubendorf L, Schöpfer A, Wagner U, Sauter G, Moch H, Willi N, Gasser TC, Mihatsch MJ. Metastatic patterns of prostate cancer: an autopsy study of 1,589 patients. Hum Pathol. 2000 May;31(5):578-583.

20. Pelger RC1, Soerdjbalie-Maikoe V, Hamdy N. Strategies for management of prostate cancer-related bone pain. Drugs Aging. 2001;18(12):899-911.

21. Sartor O, Coleman R, Nilsson S, Heinrich D, Helle SI, O'Sullivan JM, Fosså SD, Chodacki A, Wiechno P, Logue J, Widmark A, Johannessen DC, Hoskin P, James ND, Solberg A, Syndikus I, Vogelzang NJ, O'Bryan-Tear CG, Shan M, Bruland ØS, Parker C. Effect of radium-223 dichloride on symptomatic skeletal events in patients with castration-resistant prostate cancer and bone metastases: results from a phase 3 , double-blind, randomised trial. Lancet Oncol. 2014 Jun;15(7):738-746. doi: 10.1016/S1470-2045(14)70183-4.

22. Nilsson S. Radionuclide Therapies in Prostate Cancer: Integrating Radium-223 in the Treatment of Patients With Metastatic Castration-Resistant Prostate Cancer. Curr Oncol Rep. 2016 Feb;18(2):14. doi: 10.1007/s11912-015-0495-4.

23. Shore N. Radium-223 dichloride for metastatic castration-resistant prostate cancer: the urologist's perspective. Urology. 2015 Apr;85(4):717-724. doi:

10.1016/j.urology.2014.11.031. 
24. Kerr C. (223) Ra targets skeletal metastases and spares normal tissue. Lancet Oncol. 2002 Aug;3(8):453.

25. Bruland ØS1, Nilsson S, Fisher DR, Larsen RH. High-linear energy transfer irradiation targeted to skeletal metastases by the alpha-emitter 223Ra: adjuvant or alternative to conventional modalities? Clin Cancer Res. 2006 Oct 15;12(20 Pt 2):6250s-6257s.

26. Henriksen G, Breistøl K, Bruland ØS, Fodstad Ø, Larsen RH. Significant antitumor effect from bone-seeking, alpha-particle-emitting (223) Ra demonstrated in an experimental skeletal metastases model. Cancer Res. 2002 Jun 1;62(11):3120-3125.

27. Dorff TB, Gross ME. Radium 223: how can we optimize this new tool for metastatic castration-resistant prostate cancer? Am Soc Clin Oncol Educ Book. 2015: e270-273. doi: 10.14694/EdBook_AM.2015.35. e 270.

28. Nilsson S, Strang P, Aksnes AK, Franzèn L, Olivier P, Pecking A, Staffurth J, Vasanthan S, Andersson C, Bruland ØS. A randomized, dose-response, multicenter phase II study of radium-223 chloride for the palliation of painful bone metastases in patients with castration-resistant prostate cancer. Eur J Cancer. 2012 Mar;48(5):678686. doi: 10.1016/j.ejca.2011.12.023.

29. Jadvar H, Quinn DI. Targeted $\alpha$-particle therapy of bone metastases in prostate cancer. Clin Nucl Med. 2013 Dec;38(12):966-971. doi: 10.1097/RLU.0000000000000290.

30. Brady D, Parker CC, O'Sullivan JM. Bone-targeting radiopharmaceuticals including radium-223. Cancer J. 2013 Jan-Feb;19(1):71-78. doi: 10.1097/PPO.0b013e318282479b.

31. Lien LM, Tvedt B, Heinrich D. Treatment of castration-resistant prostate cancer and bone metastases with radium-223 dichloride. Int J Urol Nurs. 2015 Mar;9(1):3-13.

32. McGann S, Horton ER. Radium-223 dichloride: a novel treatment option for castration-resistant prostate cancer patients with symptomatic bone metastases. Ann Pharmacother. 2015 Apr;49(4):469-476. doi: 10.1177/1060028014565444.

33. Parker C, Nilsson S, Heinrich D, Helle SI, O'Sullivan JM, Fosså SD, Chodacki A, Wiechno P, Logue J, Seke M, Widmark A, Johannessen DC, Hoskin P, Bottomley D, James ND, Solberg A, Syndikus I, Kliment J, Wedel S, Boehmer S, Dall'Oglio M, Franzén L, Coleman R, Vogelzang NJ, O'Bryan-Tear CG, Staudacher K, GarciaVargas J, Shan M, Bruland ØS, Sartor O; ALSYMPCA Investigators. Alpha emitter radium-223 and survival in metastatic prostate cancer. N Engl J Med. 2013 Jul 18;369(3):213-223. doi: 10.1056/NEJMoa1213755. 
34. Xofigo ${ }^{\circledR}$ (radium Ra 223 dichloride) solution for injection [prescribing information]: Bayer Pharma AG; (2015) http://www.accessdata.fda.gov/drugsatfda_docs/label/2013/203971lbl.pdf

35. Sonpavde G, Pond GR, Armstrong AJ, et al. Radiographic progression by Prostate Cancer Working Group (PCWG)-2 criteria as an intermediate endpoint for drug development in metastatic castration-resistant prostate cancer. BJU Int. 2014 Dec;114(6b): E25-E31.

36. Scher HI, Morris MJ, Stadler WM, et al. Trial design and objectives for castrationresistant prostate cancer: updated recommendations from the prostate cancer clinical trials working group 3. J Clin Onc 2016:34:1402-18.

37. https://www.eortc.be/services/doc/ctc/CTCAE_4.03_2010-06-

\section{4_QuickReference_5x7.pdf}

38. http://ecog-acrin.org/resources/ecog-performance-status

39. Mottet N, Bellmunt J, Bolla M, et al. EAU-ESTRO-SIOG Guidelines on Prostate Cancer. Part 1: Screening, Diagnosis, and Local Treatment with Curative Intent. Eur Urol. 2017 Apr;71(4):618-629.

40. Weinmann S, Van Den Eeden SK, et al. Immunohistochemical expression of ERG in the molecular epidemiology of fatal prostate cancer study. Prostate 2013; 73: 1371 1377.

41. Fizazi K, Scher HI, Molina A, et al. Abiraterone acetate for treatment of metastatic castration-resistant prostate cancer: final overall survival analysis of the COU-AA-301 randomised, double-blind, placebo-controlled phase 3 study. Lancet Oncol. 2012; 13 : 983-992.

42. Sternberg CN, Castellano D, Daugaard G, et al. Abiraterone acetate for patients with metastatic castration-resistant prostate cancer progressing after chemotherapy: final analysis of a multicentre, open-label, early-access protocol trial. Lancet Oncol. 2014; 15: $1263-1268$.

43. Reig Ò, Marín-Aguilera M, Carrera G, et al. TMPRSS2-ERG in Blood and Docetaxel Resistance in Metastatic Castration-resistant Prostate Cancer. Eur Urol. 2016 Nov;70(5):709-713.

44. Song W, Kwon GY, Kim JH, et al. Immunohistochemical staining of ERG and SOX9 as potential biomarkers of docetaxel response in patients with metastatic castration- 
resistant prostate cancer. Oncotarget. 2016 Dec 13;7(50):83735-83743. doi: 10.18632/oncotarget.13407.

45. Rajpar et al. The benefit of combining docetaxel to androgen deprivation therapy in localized and metastatic castration-sensitive prostate cancer as predicted by ERG status: An analysis of two GETUG phase III trials. Presented at the 2017 ASCO Annual Meeting on 5 June 2017. Available at: https://www.urotoday.com/conferencehighlights/asco-2017/asco-2017-prostate-cancer/96278-asco-2017-the-benefit-ofcombining-docetaxel-to-androgen-deprivation-therapy-in-localized-and-metastaticcastration-sensitive-prostate-cancer-as-predicted-by-erg-status-an-analysis-of-twogetug-phase-iii-trials.html

46. Hussain M, Goldman B, Tangen C, et al. Prostate-specific antigen progression predicts overall survival in patients with metastatic prostate cancer: data from Southwest Oncology Group Trials 9346 (Intergroup Study 0162) and 9916. Journal of Clinical Oncology 2009;27(15):2450-6.

47. Modi D, Hwang C, Mamdani H, Kim S, Gayar H, Vaishampayan U, Joyrich R, Heath EI. Radium-223 in Heavily Pretreated Metastatic Castrate-Resistant Prostate Cancer. Clin Genitourin Cancer. 2016 Mar 10. pii: S1558-7673(16)30056-8. doi: 10.1016/j.clgc.2016.03.002.

48. McNamara MA, George DJ. Pain, PSA flare, and bone scan response in a patient with metastatic castration-resistant prostate cancer treated with radium-223, a case report. BMC Cancer. 2015 May 7; 15:371. doi: 10.1186/s12885-015-1390-y.

49. Hoskin P, Sartor O, O'Sullivan JM, Johannessen DC, Helle SI, Logue J, Bottomley D, Nilsson S, Vogelzang NJ, Fang F, Wahba M, Aksnes AK, Parker C. Efficacy and safety of radium-223 dichloride in patients with castration-resistant prostate cancer and symptomatic bone metastases, with or without previous docetaxel use: a prespecified subgroup analysis from the randomised, double-blind, phase 3 ALSYMPCA trial. Lancet Oncol. 2014 Nov;15(12):1397-1406. doi: 10.1016/S14702045(14)70474-7.

50. Autio KA, Bennett AV, Jia X, Fruscione M, Beer TM, George DJ, Carducci MA, Logothetis CJ, Kane RC, Sit L, Rogak L, Morris MJ, Scher HI, Basch EM. Prevalence of pain and analgesic use in men with metastatic prostate cancer using a patientreported outcome measure. J Oncol Pract. 2013 Sep;9(5):223-9. doi:

10.1200/JOP.2013.000876. 
51. Salvati M, Frati A, Russo N, Brogna C, Piccirilli M, D'Andrea G, Occhiogrosso G, Pichierri A, Caroli E. Brain metastasis from prostate cancer. Report of 13 cases and critical analysis of the literature. J Exp Clin Cancer Res. 2005 Jun;24(2):203-207.

52. Gavrilovic IT, Posner JB. Brain metastases: epidemiology and pathophysiology. J Neurooncol. 2005 Oct;75(1):5-14.

53. Caffo O, Gernone A, Ortega C, Sava T, Cartenì G, Facchini G, Re GL, Amadio P, Bortolus R, Pagliarulo V, Prati V, Veccia A, Galligioni E. Central nervous system metastases from castration-resistant prostate cancer in the docetaxel era. J Neurooncol. 2012 Mar;107(1):191-196. doi: 10.1007/s11060-011-0734-y.

54. Caffo O, Veccia A, Russo L, Galligioni E. Brain Metastases From Prostate Cancer. Future Oncol. 2012 Dec;8(12):1585-1595. doi: 10.2217/fon.12.156.

55. Chi KN, Kheoh T, Ryan CJ, et al. A prognostic index model for predicting overall survival in patients with metastatic castration-resistant prostate cancer treated with abiraterone acetate after docetaxel. Ann Oncol. 2016; 27: 454-460.

56. de Bono JS, Smith MR, Saad F, et al. Subsequent chemotherapy and treatment patterns after abiraterone acetate in patients with metastatic castration-resistant prostate cancer: post hoc analysis of COU-AA-302. Eur Urol. 2017; 71: 656-664.

57. George S, Motzer RJ, Hammers HJ, et al. Safety and efficacy of nivolumab in patients with metastatic renal cell carcinoma treated beyond progression: a subgroup analysis of a randomized clinical trial. JAMA Oncol. 2016; 2: 1179-1186.

58. von Minckwitz G, Puglisi F, Cortes J, et. al. Bevacizumab plus chemotherapy versus chemotherapy alone as second-line treatment for patients with HER2-negative locally recurrent or metastatic breast cancer after first-line treatment with bevacizumab plus chemotherapy (TANIA). Lancet Oncol. 2014; 15: 1269-1278.

59. Extra JM, Antoine EC, Vincent-Salomon A, et al. Efficacy of trastuzumab in routine clinical practice and after progression for metastatic breast cancer patients: the observational Hermine study. Oncologist. 2010; 15: 799-809.

60. Kubicka S, Greil R, André T, et al. Bevacizumab plus chemotherapy continued beyond first in patients with metastatic colorectal cancer previously treated with bevacizumab plus chemotherapy ML18147 study KRAS subgroup findings. Ann Oncol. 2013; 24: 2342-2349. 
61. Cunningham D, Humblet Y, Siena S, et al. Cetuximab monotherapy and cetuximab plus irinotecan in irinotecan-refractory metastatic colorectal cancer. $N$ Engl J Med. 2004; 351: 337-345.

62. Taylor CD, Elson P, Trump DL. Importance of continued testicular suppression in hormone-refractory prostate cancer. J Clin Oncol.1993; 11: 2167-2172. .

63. Hussain, M., Wolf M, Marshall E, et al. Effects of continued androgen-deprivation therapy and other prognostic factors on response and survival in phase II chemotherapy trials for hormone-refractory prostate cancer: a Southwest Oncology Group report. J Clin Oncol. 1994; 12: 1868-1875.

64. Sun S, Sprenger CC, Vessella RL, et al. Castration resistance in human prostate cancer is conferred by a frequently occurring androgen receptor splice variant. J Clin Invest. 2010; 120:2715-2730.

65. Nakata D, Nakao S, Nakayama K, et al. The RNA helicase DDX39B and itsparalog DDX39A regulateandrogen receptor splicevariant AR-V7 generation. Biochem Biophys Res Commun. 2017; 483: 271-276.

66. Quaresma AJ, Sievert R, Nickerson JA. Regulation of mRNA export bythe PI3 kinase/AKT signaltransductionpathway. Mol Biol Cell. 2013; 24: 1208-1221.

67. Hotte SJ, Joshua AM, Torri V, et al. IND 205B: A phase II study of the PI3K inhibitor PX-866 and continued abiraterone/prednisone in patients with recurrent or metastatic castration resistant prostate cancer (CRPC) with PSA progression on abiraterone/prednisone. J Clin Oncol. 2015; 33(suppl 7): abstr 279.

68. Ni Z, Tang J, Cai Z, et al. A new pathway of glucocorticoid action for asthma treatment through the regulation of PTEN expression. Respir Res. 2011; 12: 47.

69. Miller AB, Hoogstraten B, Staquet M, et al. Reporting results of cancer treatment. Cancer. 1981; 47: 207-214.

70. Therasse P, Arbuck SG, Eisenhauer EA, et al. New guidelines to evaluate the response to treatment in solid tumors (RECIST Guidelines). J Natl Cancer Inst. 2000; 92: 205216.

71. Eisenhauer EA, Therasse P, Bogaerts J, et al. New response evaluation criteria in solid tumours: revised RECIST guideline (version 1.1). Eur J Cancer. 2009; 45: 228-247.

72. Bubley GJ, Carducci M, Dahut W, et al. Eligibility and response guidelines for phase II clinical trials in androgen-independent prostate cancer: recommendations from the Prostate-Specific Antigen Working Group. J Clin Oncol. 1999; 17: 3461-3467. 